\title{
The Functional Resonance Analysis Method: A Performance Appraisal Tool for Risk Assessment and Accident Investigation in Complex and Dynamic Socio-Technical Systems
}

\author{
Issa Diop'1, Georges Abdul-Nour ${ }^{1}$, Dragan Komljenovic ${ }^{2}$ \\ ${ }^{1}$ Department of Industrial Engineering, University of Quebec in Trois-Rivieres (UQTR), Trois-Rivieres, Canada \\ ${ }^{2}$ Hydro-Quebec Research Institute (IREQ), Varennes, Canada \\ Email: issa.diop.1@etsmtl.net, issa.diop@uqtr.ca
}

How to cite this paper: Diop, I., AbdulNour, G., \& Komljenovic, D. (2022). The Functional Resonance Analysis Method: A Performance Appraisal Tool for Risk Assessment and Accident Investigation in Complex and Dynamic Socio-Technical Systems. American Journal of Industrial and Business Management, 12, 195-230.

https://doi.org/10.4236/ajibm.2022.122013

Received: January 21, 2022

Accepted: February 25, 2022

Published: February 28, 2022

Copyright $\odot 2022$ by author(s) and Scientific Research Publishing Inc. This work is licensed under the Creative Commons Attribution International License (CC BY 4.0).

http://creativecommons.org/licenses/by/4.0/

\begin{abstract}
This article aims at systematically reviewing the entire collection of papers published on the development and application of the functional resonance analysis method (FRAM) in the last decade. The Preferred Reporting Item for Systematic Reviews and Meta-Analyses (PRISMA) methodology has been utilized as a formal systematic literature review standard for data gathering. The analysis encompassed 47 documents devoted to this subject matter, systematically retrieved from the online database Scopus. The findings revealed the necessity for the development of systemic safety assessment approaches to explain performance variability of complex and dynamic socio-technical systems (risk assessment or accident investigation). Indeed, it is crucial to rigorously assess the performance variability throughout safety appraisal since unexpected performance variability can combine in undesirable manners and consequently denotes a threat for safety and losses of human life. However, the FRAM process has some pros and cons as discussed in this review. Consequently, other assessment methods exist to complement the FRAM process.
\end{abstract}

\section{Keywords}

Functional Resonance Analysis Method (FRAM), Resilience Engineering (RE), Decision-Making, Strategic Asset Management (SAM), Risk Management (RM), Industry 4.0, Preferred Reporting Items for Systematic Reviews and Meta-Analyses (PRISMA)

\section{Introduction}

The proper working of our society needs complex and dynamic socio-technical 
systems. The latter consists of, for e.g., electrical power utilities, nuclear power plants, transportation networks, air traffic systems, health care systems, railway traffic grids, maritime mining systems, maritime transportation systems, oil platforms, gas-and-water distribution systems, etc.

Conventionally, risk and accidents have been investigated by focusing on how failures or malfunctions could occur and how the consequences could disseminate through the system (Hollnagel, 2012; Diop et al., 2021). Many scholars have been interested in studying everyday work as executed by practitioners, namely "work as done", for the insight of how safety is coined in practice, instead of concentrating on "work as imagined" by management or regulations (legal liabilities), with the aim of optimizing the company's value chain (Hollnagel, 2012; de Vries, 2017). Resilience engineering is a well-known approach suggested in risk management and uncertainties analysis to investigate the ability of a system to adapt and generate a fruitful result in everyday operations (Diop et al., 2021). Hollnagel (2013) defined resilience engineering as "The intrinsic ability of a system to adjust its functioning prior to, during, or following changes and disturbances, so that it can sustain required operations under both expected and unexpected conditions". Hence, the purpose stands for the shift of interest from "Safety I" philosophy to "Safety II" philosophy toward everyday operations or "events". The "Safety I" thinking focuses on what goes wrong rather than what goes right ("Safety II" thinking) (Hollnagel, 2014). Therefore, one should examine how socio-technical work is achieved in practice and in a daily basis to grasp safety.

The FRAM idea was developed to meet the benefit in "going behind human error and beyond the failure concept" by modelling the functions ${ }^{1}$ that are required for everyday performance to be successful in congruence with the Resilience Engineering approach (RE) that constantly claimed that safety is beyond the non-appearance of failures (Hollnagel, 2012). The FRAM relies on the principle of "equivalence of successes and failures" and the principle of "approximate adjustments". Therefore, in fact, performance is continuously variable. The performance variability of a given function might impact the performance variability of other functions and in this manner cause a "functional resonance" or non-linear effects (analogized to stochastic resonance among signals with fluctuating amplitudes and frequencies) (Hollnagel, 2012).

This new idea emerged at the beginning of 2004 driven by the limitations of deterministic and probabilistic methods to appreciate complex and dynamic socio-technical systems' comportment (Patriarca et al., 2020; Hollnagel, 2004).

1"Function: In the FRAM, a function represents the means that are necessary to achieve a goal. More generally, a function refers to the activities-or set of activities-that are required to produce a certain outcome. A function describes what people-individually or collectively-have to do in order to achieve a specific aim. A function can also refer to what an organization does: for example, the function of an emergency room is to treat incoming patients. A function can finally refer to what a technological system does either by itself (an automated function) or in collaboration with one or more humans (an interactive function or co-agency)" (A FRAM Glossary https://functionalresonance.com/a-fram-glossary.html). 
Earlier, the precursors have adopted the FRAM as a socio-technical approach to investigate accident and assess safety (systemic functional approach) in complex socio-technical systems ${ }^{2}$ (Hollnagel, 2004; Hollnagel et al., 2008; Lundblad et al., 2008; Sawaragi et al., 2006; Woltjer \& Hollnagel, 2007). Today, the FRAM has been established to model complex and dynamic socio-technical systems to apprehend not only why things sometimes fail but also why they normally succeed.

It is worth emphasizing that, in practical terms, this method investigates how occupational activities occur retrospectively ("analyses of accidents or events") or prospectively ("analyses of current work domain or envisioned scenarios for risk management”, etc.) by examining work activities with the purpose of understanding how work is accomplished every day and how things turned wrong or right (Patriarca et al., 2020). Nevertheless, the FRAM is a method instead of being a model. This denotes that it does not express any hypotheses regarding neither how the studied system is designed or structured, nor what are the potential causes and relations between causes and consequences, nor in search of failures and abnormal functioning (Hollnagel, 2012). The FRAM expresses results in respect of how functions become coupled and how daily performance variability can resonate (i.e., add force to each other and so trigger the variability of one function to be high) (Hollnagel, 2012; Patriarca et al., 2020).

Currently, the FRAM is gaining popularity accounting for a research component of major interest in the scientific community. It is well supported by several ad hoc working groups (The FRAMily meeting) and is applied in various high-risk fields such Nuclear Power, Aircraft De-icing, Air Traffic Management Safety Assessment, Health Care, Railway Traffic, Maritime Mining, Maritime Transportation etc. (for e.g.: Hollnagel, Woods, \& Leveson, 2012; Hollnagel, 2012; Hollnagel, 2018; Hollnagel et al., 2014; Hounsgaard, 2016; Macchi, 2010; Nemeth \& Hollnagel, 2016; Slater et al., 2022; Huang et al., 2019; Lee \& Chung, 2018; Slim, 2020). However, studies systematically reviewing the scientific production on this topic is lacking as mentioned by Patriarca et al. (2020). On these grounds, this article focuses on systematically reviewing the whole collection of papers published on the development and application of the FRAM in the last decade in complex and dynamic socio-technical systems. The PRISMA guidelines have been used as a proper systematic literature review process to methodically collect and analyze data.

The remainder of this paper is structured as follows: Section II introduces the methodology of the literature review. Section 3 summarizes the results of the bibliometric analysis. Section 4 provides a discussion of the key findings. Finally, Section 5 concludes the review and provides new research targets.

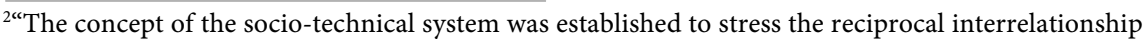
between humans and machines and to foster the program of shaping both the technical and the social conditions of work, in such a way that efficiency and humanity would not contradict each other any longer.... It aims at understanding the complexity of real situations rather than at analyzing separated aspects. So, the idea of sociotechnical systems was designed to cope with the theoretical and practical problems of working conditions in industry" (Ropohl, 1999).
} 


\section{Methodology}

A systematic and critical literature search has been conducted to have a mapping of the state of the art relevant to this topic. We quantify the scientific production and measure its quality and impact. A computerized bibliometric ${ }^{3}$ analysis was conducted for papers published between January 1, 2011, and December 1, 2021. Bibliometrix analysis helps assess both the qualitative and quantitative research endeavors as well as the suitability in a field of study (Afuye et al., 2021; Ellegaard \& Wallin, 2015). To illustrate the results of the dada search and paper selection process, the PRISMA guidelines has been applied as a recognized systematic literature review model for data collecting and processing (Moher et al., 2009). The PRISMA is a checklist ensuring that the paper selection process is replicable and obvious. Figure 1 depicts the PRISMA approach for the literature search. Data were systematically retrieved from the online database Scopus on December 15, 2021. Furthermore, a backward analysis was conducted to assess the publication trend of the scientific papers on the FRAM in complex and dynamic socio-technical systems. To identify all references published within the survey period related to this subject matter, the query string is defined as follows:

(Title ("resilience" and "functional resonance analysis method") or title ("functional resonance analysis method")) and pub year $>1999$ and (limit-to (language, “English")).

The initial search retrieves an amount of 47 papers devoted to the development and application of the functional resonance analysis method (FRAM) in

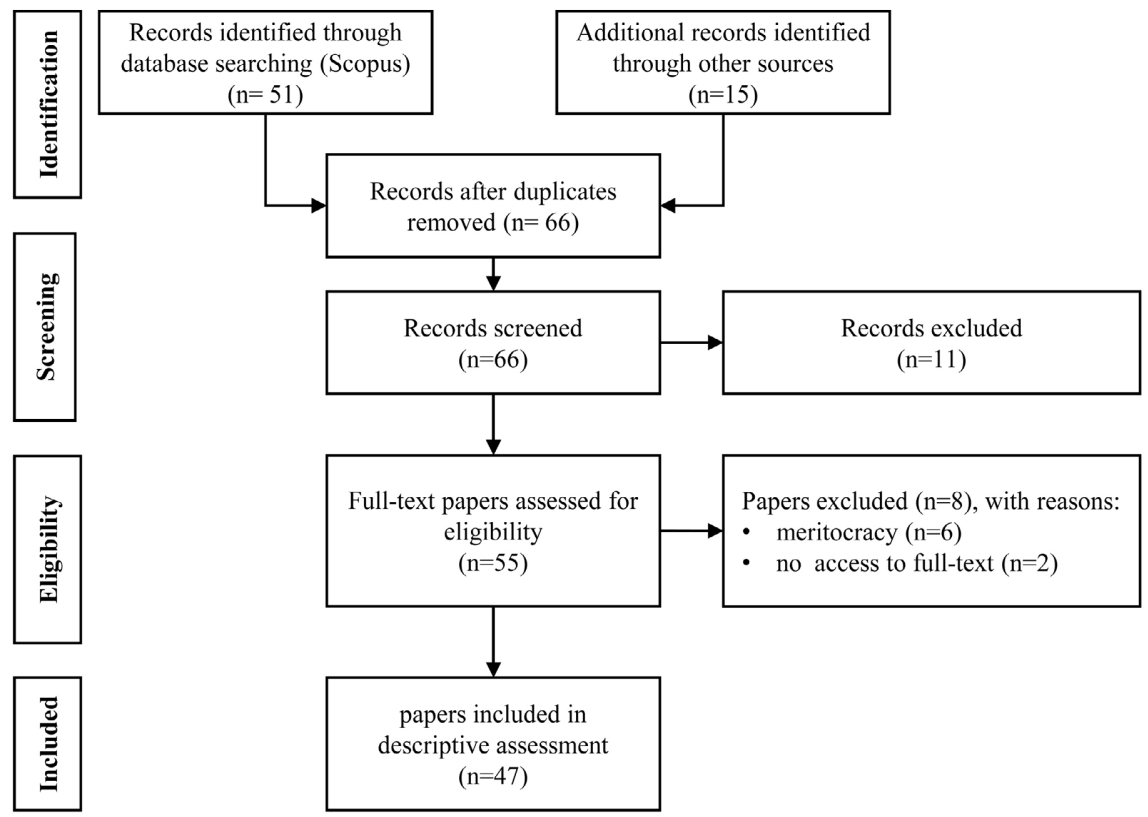

Figure 1. PRISMA approach for the literature search. (Source: own representation).

\footnotetext{
3"Bibliometrics is usually used for the quantitative research assessment of academic output, and it is starting to be used for practice-based research. Concretely, bibliometrics is a set of methods used to study or measure texts and information, especially in big datasets" (Cobo et al., 2011).
} 
the last decade. Further analysis was necessary to identify whether the document is appropriate or not. Hence, each paper was subjected to a further examination of its abstract and keywords. Therefore, if the paper appeared to be relevant, it was selected to be utterly read and investigated. Moreover, snowball approach was performed by examining the cited references of the earlier chosen papers to find more papers relevant for this study. Precisely, documents were included in the analysis if they were published as a journal paper, a conference paper, or a book, written in English and their abstract indicated that the document focuses on FRAM. Each document was read entirely to ascertain whether its content is appropriate to our review or not. The selected manuscripts (i.e., documents matching the inclusion criteria, including their metadata) were then exported to the reference management software Endnote and transformed into $\mathrm{R}$ data frame utilizing the opensource R package BIBLIOMETRIX (Aria \& Cuccurullo, 2017). Though, all papers were not discussed in detail to keep the length of this review within appropriate limits. Merely those papers that are most suitable and relevant to this analysis were discussed in depth.

\section{Results-Descriptive Analysis}

The descriptive analysis describes the annual research progress, the leading productive authors, papers, countries, and most relevant keywords. This section presents the bibliometric analysis outcomes of the research trends and academic collaboration networks. It gives a mapping of the annual research growth, the topic structure (co-occurrence network, thematic maps, social structure, etc.), as well as the foremost productive authors, papers, countries, the most recurring keywords, and keywords Plus'.

\subsection{Main Findings about the Collection}

Table 1 shows the main findings about the collection on the functional resonance analysis method (FRAM).

Figure 2 illustrates the annual scientific production associated with this subject matter. An annual percentage growth rate of $6.5 \%$ of publications was observed. The number of publications declined substantially between 2018 and 2019 before a high peak was observed in 2021. This increase corroborates the growing interest in using the FRAM methodology for the assessment of complex and dynamic socio-technical systems (environments characterized by high mishap hazard). These metrics infer that the annual number of papers published within the survey period is stable. Therefore, this research area is steady in respect of volume of publications (Afuye et al., 2021; Ellegaard \& Wallin, 2015).

\subsection{Sources Impact}

Table 2 shows the most relevant sources. Reliability Engineering and System 4"Keywords: Author Keywords, those provided by the original authors. Keywords Plus: those extracted from the titles of the cited references. Keywords Plus, generated by an automatic computer algorithm, are words or phrases that appear frequently in the titles of an article's references and not necessarily in the title of the article or as Author Keywords" (Zhang et al., 2016). 
Table 1. Main findings about the collection on FRAM (Source: own representation).

\begin{tabular}{|c|c|c|c|}
\hline & \multicolumn{3}{|c|}{ DOCUMENT TYPES } \\
\hline Description & Results & Description & Results \\
\hline Timespan & 2011:2022 & Article & 30 \\
\hline Sources (journals, books, etc.) & 29 & Book & 1 \\
\hline Documents & 47 & Book chapter & 1 \\
\hline $\begin{array}{l}\text { Average years from } \\
\text { publication }\end{array}$ & 2.43 & Conference paper & 12 \\
\hline $\begin{array}{l}\text { Average citations per } \\
\text { documents }\end{array}$ & 131.4 & Review & 3 \\
\hline $\begin{array}{l}\text { Average citations per } \\
\text { year per doc. }\end{array}$ & 23.01 & - & - \\
\hline References & 2043 & - & - \\
\hline AUTHORS & & $\begin{array}{l}\text { AUTHORS } \\
\text { COLLABORATION }\end{array}$ & \\
\hline Description & Results & Description & Results \\
\hline Authors & 151 & Single-authored documents & 3 \\
\hline Author appearances & 179 & Documents per author & 0.311 \\
\hline $\begin{array}{l}\text { Authors of single-authored } \\
\text { docs. }\end{array}$ & 3 & Authors per document & 3.21 \\
\hline $\begin{array}{l}\text { Authors of multi-authored } \\
\text { docs. }\end{array}$ & 148 & Co-authors per documents & 3.81 \\
\hline- & - & Collaboration index & 3.36 \\
\hline DOCUMENT CONTENTS & & - & - \\
\hline Description & Results & - & - \\
\hline Keywords Plus (ID) & 416 & - & - \\
\hline Author's keywords (DE) & 112 & - & - \\
\hline
\end{tabular}

Table 2. Most relevant sources. (Source: own representation).

\begin{tabular}{lccccc}
\hline \multicolumn{1}{c}{ Sources } & Papers & $\begin{array}{r}\text { Impact } \\
\text { Factor }\end{array}$ & H-index & SJR $^{7}$ & SNIP $^{8}$ \\
\hline Reliability Engineering and System Safety & 8 & 7.030 & 146 & 1.761 & 2.707 \\
Safety Science & 6 & 4.877 & 111 & 1.178 & 2.473 \\
Cognition Technology and Work & 4 & 2.920 & 36 & 0.518 & 1.430 \\
Applied Ergonomics & 2 & 4.170 & 98 & 1.093 & 2.489 \\
Lecture Notes in Mechanical Engineering & 2 & 0.55 & 16 & 0.150 & 0.287 \\
\hline
\end{tabular}

${ }^{5}$ Impact Factor. "The number of citations of articles published in the source journal in the preceding two years divided by the number of items published in that journal in the previous two years". ${ }^{6}$ The h-index attempts to "measure both the productivity and impact of the published work of a scientist or scholar". "A scientist has index $h$ if $h$ of his or her $N_{p}$ papers have at least h citations each and the other $\left(N_{p}-h\right)$ papers have $\leq h$ citations each" (Hirsch, 2005).

${ }^{7}$ SCImago Journal Rank (SJR): "SJR is weighted by the prestige of a journal. Subject field, quality, and reputation of the journal have a direct effect on the value of a citation".

${ }^{8}$ SNIP (Source Normalized Impact per Paper): SNIP measures a source's contextual citation impact by weighting citations based on the total number of citations in a subject field. It helps you make a direct comparison of sources in different subject fields. 




Figure 2. Annual scientific production. (Source: own representation).

Safety ranks first with a total number of 8 publications followed by Safety Science and Cognition Technology and Work with respectively 6 and 4 publications as shows in Figure 3 depicting the source clustering through Bradford's law. Figure 4 shows the Source growth.

\subsection{Authors Impact}

Table 3 shows the most relevant authors. Costantino F., Di Gravio G., Patriarca R., and Hollnagel E. rank first followed by Kaya G.K. and Haddad A.N.

Table 4 shows the most cited authors. Hollnagel E. ranks first with 608 citations followed by Costantino F., Di Gravio G., Patriarca R. Figure 5 depicts the citation network, i.e., the citations within the collection of papers. It provides information about how authors relate to others in this specific field of research.

Figure 6 depicts the top-authors' production over the time. A given line embodies an author timeline. The bubble at a particular year implies that the author published at least a paper in that year. The bubble size is proportional to the total number of papers that author published in that year. Finally, the color intensity is proportional to the total number of citations per year of the document published in that year.

Figure 7 illustrates the author productivity through Lotka's law. The latter illustrates "the frequency of publication by authors in any given field. As the number of articles published increases, authors producing that many publications become less frequent' (Lotka, 1926). The general formula of Lotka's law is expressed as follows: $Y=C / X^{n}$ (where $X$ is the number of publications, $Y$ the relative frequency of authors with $X$ publications, and $n$ and $C$ are constants depending on the specific field $(n \approx 2)$. Only $3.30 \%$ of the authors have published four papers. Most of them (88.70\%) have authored one paper. 
Table 3. Most relevant authors. (Source: own representation).

\begin{tabular}{lcc}
\hline \multicolumn{1}{c}{ Authors } & Articles & $\begin{array}{c}\text { Total link } \\
\text { strength }\end{array}$ \\
\hline $\begin{array}{l}\text { Costantino F. (Patriarca et al., 2020; Patriarca et al., 2018; } \\
\text { Patriarca et al., 2017a; Patriarca et al., 2017b) }\end{array}$ & 4 & 156 \\
$\begin{array}{l}\text { Di Gravio G. (Patriarca et al., 2020; Patriarca et al., 2018; } \\
\text { Patriarca et al., 2017a; Patriarca et al., 2017b) }\end{array}$ & 4 & 156 \\
$\begin{array}{l}\text { Patriarca R. (Patriarca et al., 2020; Patriarca et al., 2018; } \\
\text { Patriarca et al., 2017a; Patriarca et al., 2017b) }\end{array}$ & 4 & 156 \\
$\begin{array}{l}\text { Hollnagel E. (Hollnagel, 2012; Patriarca et al., 2020; Raben } \\
\text { et al., 2018; França et al., 2021) }\end{array}$ & 4 & 47 \\
$\begin{array}{l}\text { Kaya G.K. (Kaya et al., 2019, 2021; Kaya \& Hocaoglu, } \\
\text { 2020) }\end{array}$ & 3 & 108 \\
$\begin{array}{l}\text { De Carvalho P.V.R. (De Carvalho, 2011; Cabrera et al., } \\
\text { 2014) }\end{array}$ & 2 & 52 \\
$\begin{array}{l}\text { Haddad A.N. (França et al., 2021, Rosa et al., 2015) } \\
\text { Smoczyński P. (Smoczyński et al., 2018a; Smoczyński et } \\
\text { al., 2018b) }\end{array}$ & 2 & 26 \\
$\begin{array}{l}\text { Bellini E. (Bellini et al. (2020), Bellini et al. (2016) } \\
\text { McCloskey R. (Salehi et al., 2021; McGill et al., 2021) }\end{array}$ & 2 & 28 \\
\begin{tabular}{l} 
Pardo-Ferreira, M.D.C. (Pardo-Ferreira et al., 2019) \\
\hline
\end{tabular} & 2 & 7 \\
\hline
\end{tabular}

Table 4. Most cited authors (Source: own representation).

\begin{tabular}{ccc}
\hline Authors & Citations & Total link strength \\
\hline Hollnagel E. & 608 & 82 \\
Costantino F. & 181 & 156 \\
Di Gravio G. & 181 & 156 \\
Patriarca R. & 181 & 156 \\
De Carvalho P.V.R. & 163 & 108 \\
Haddad A.N. & 55 & 52 \\
Rosa L.V. & 53 & 52 \\
Bellini E. & 42 & 7 \\
Nesi P. & 42 & 7 \\
Tronci M. & 39 & 34 \\
Pardo-Ferreira, M.D.C. & 36 & 62 \\
Kaya G.K. & 20 & 47
\end{tabular}

\footnotetext{
9"A link is a connection or a relation between two items. Items are the objects of interest, items may for example be publications, researchers, or terms. Each link has a strength, represented by a positive numerical value. The higher this value, the stronger the link" (Van Eck \& Waltman, 2013). 10"The size of the label and the circle of an item is determined by the weight of the item. The higher the weight of an item, the larger the label and the circle of the item. The color of an item is determined by the cluster to which the item belongs. The closer two items are located to each other, the stronger their relatedness" (Lundblad et al., 2008).
} 


\subsection{Social Structure-Collaboration Analysis}

The collaboration analysis provides information about how authors and countries interact to others in a particular domain of research. Figure 8 below depicts the author collaboration network (co-author network) classified in 4 clusters $^{10}$. It

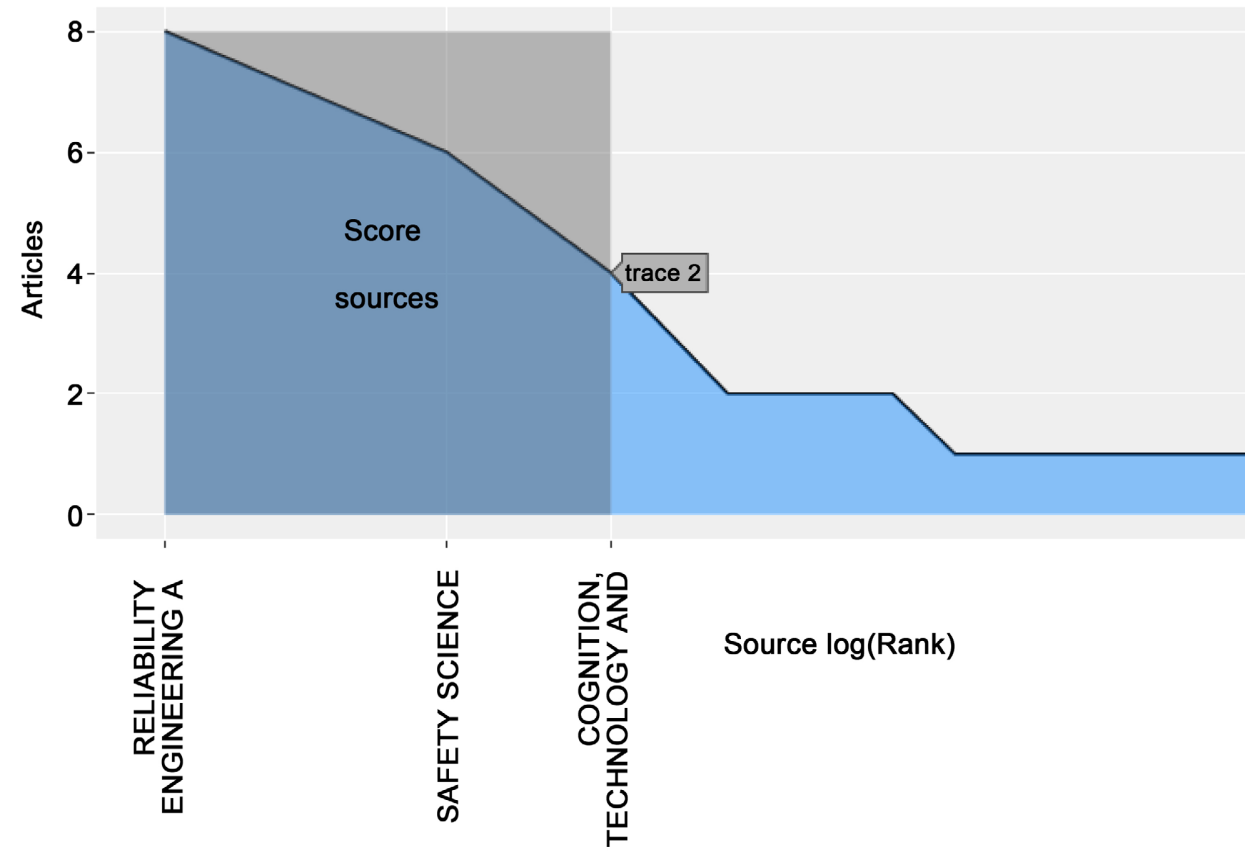

Figure 3. Source clustering through Bradford's law (Source: own representation).

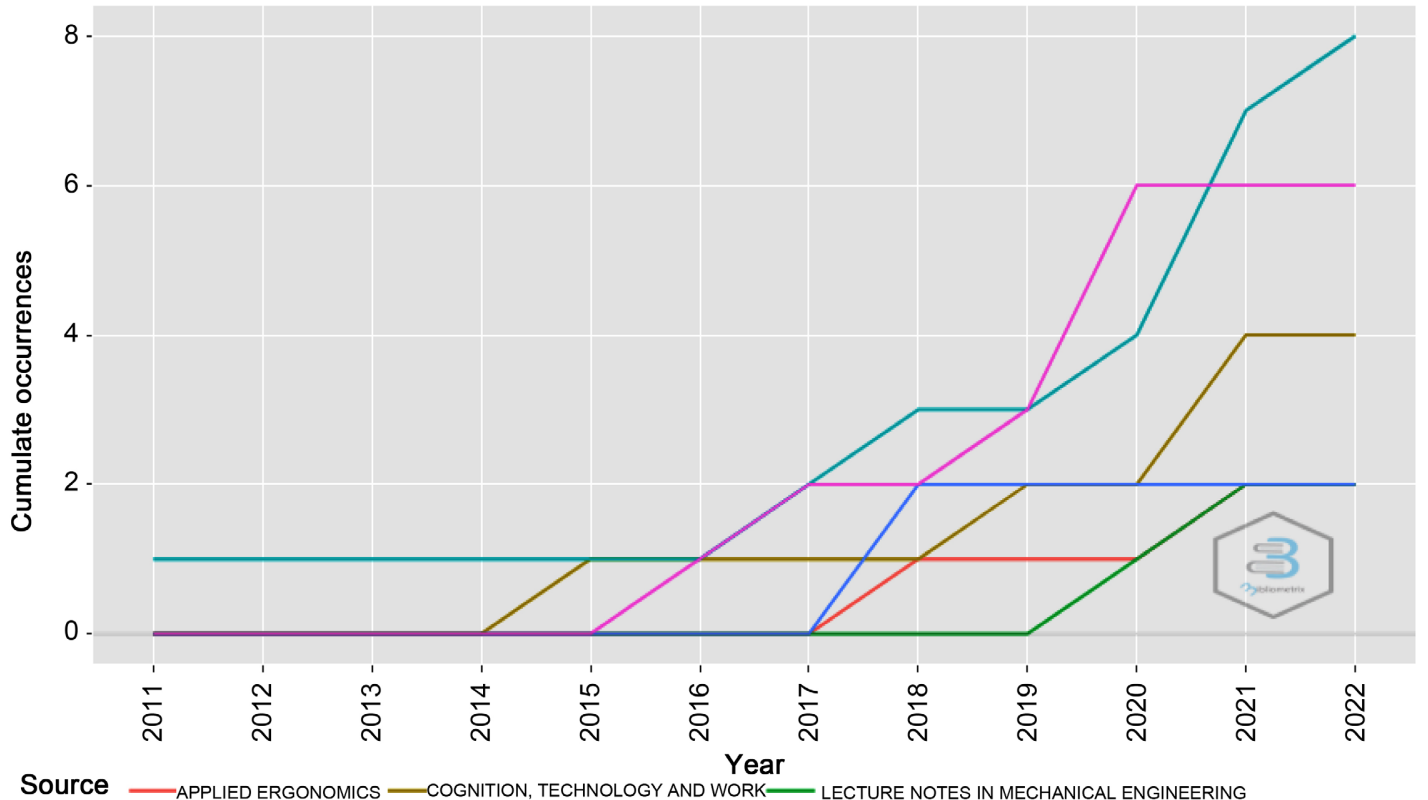

— RELIABILITY ENGINEEERING AND SYSTEM SAFETY

SAFETY AND RELIABILITY-SAFE SOCIETIES IN A CHANGING WORLD-PROCEEDINGS OF THE 28TH INTERNATIONAL EUROPEAN SAFETY AND RELIABILITY CONFERENCE

- SAFETY SCIENCE

Figure 4. Source growth: cumulate occurrences. (Source: own representation). 


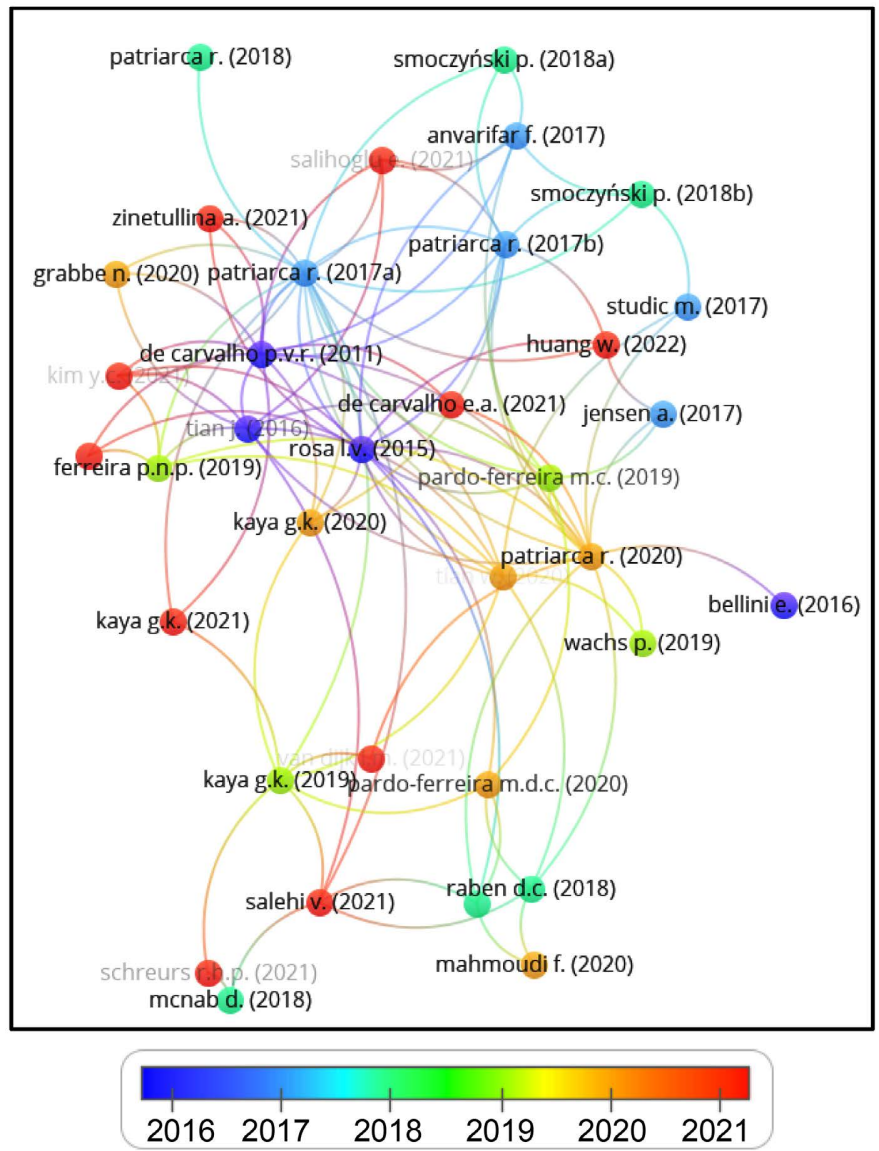

Figure 5. Citation network. (Source: own representation).

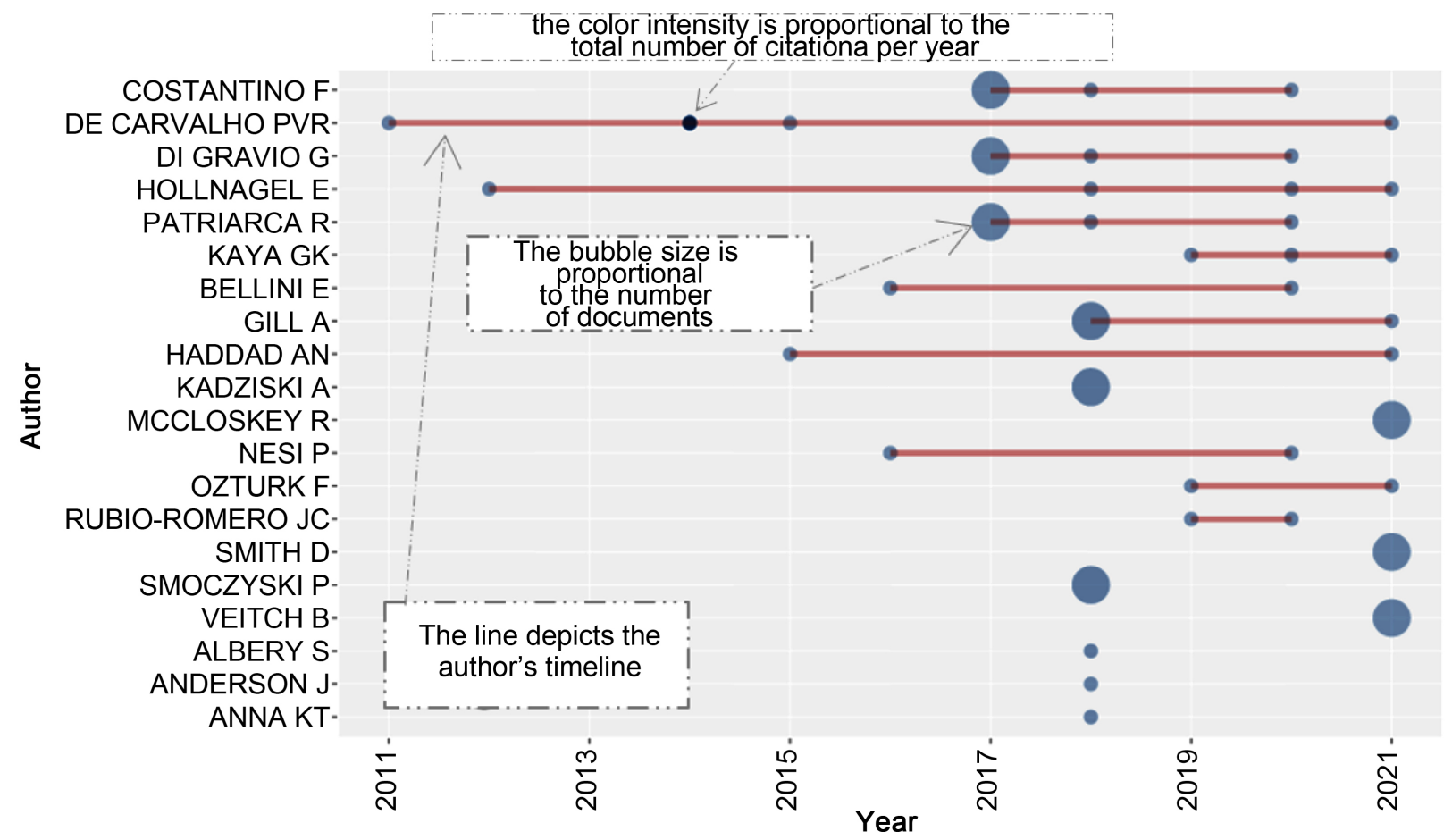

Figure 6. Top-authors' production over the time. (Source: own representation). 


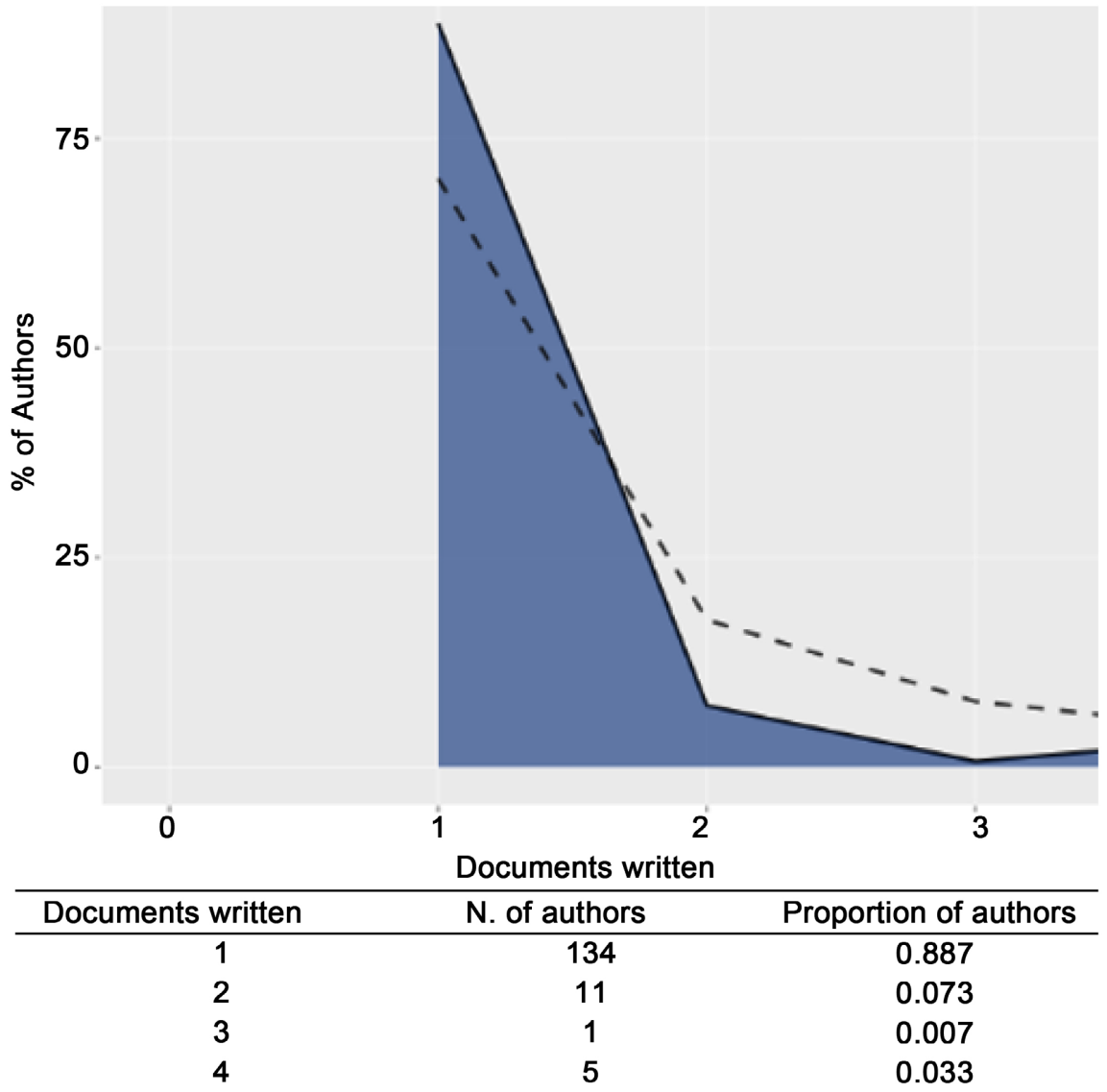

Figure 7. Author productivity through Lotka's law. (Source: own representation).



Figure 8. Co-authorship analysis (scores: average papers per year). (Source: own representation). 
finds research groups of scholars and pivotal authors. The size of a link in the network depends on the relationship between the authors. The higher the relationship, the stronger the edge size. Figure 9 represents the authors' bibliographic coupling categorized in four clusters. The relatedness of authors is established based on the number of references they shared or cited ("Bibliographic coupling occurs when two works reference a common third work in their bibliographies. It is an indication that a probability exists that the two works treat a related subject matter" (Martyn, 1964)). Figure 10 and Table 5 describe the

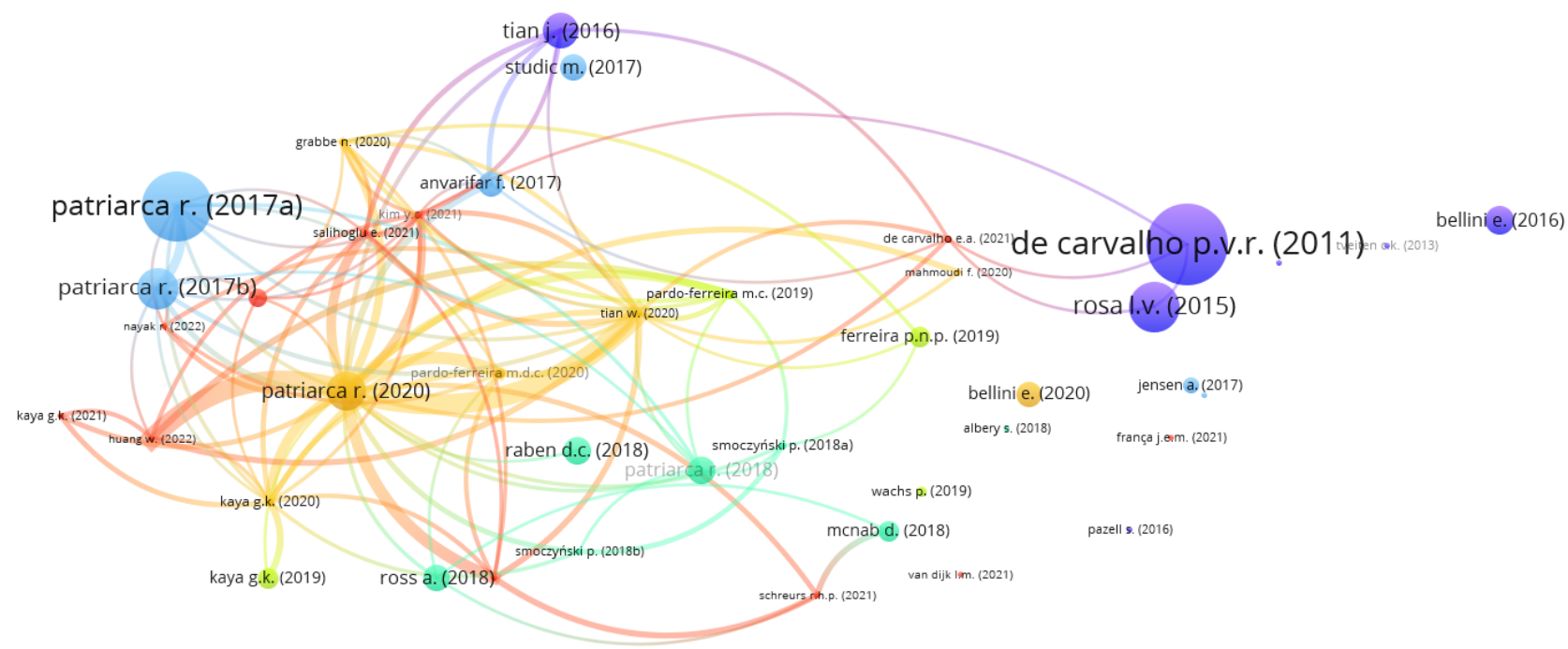

Figure 9. Authors bibliographic coupling. (Source: own representation).

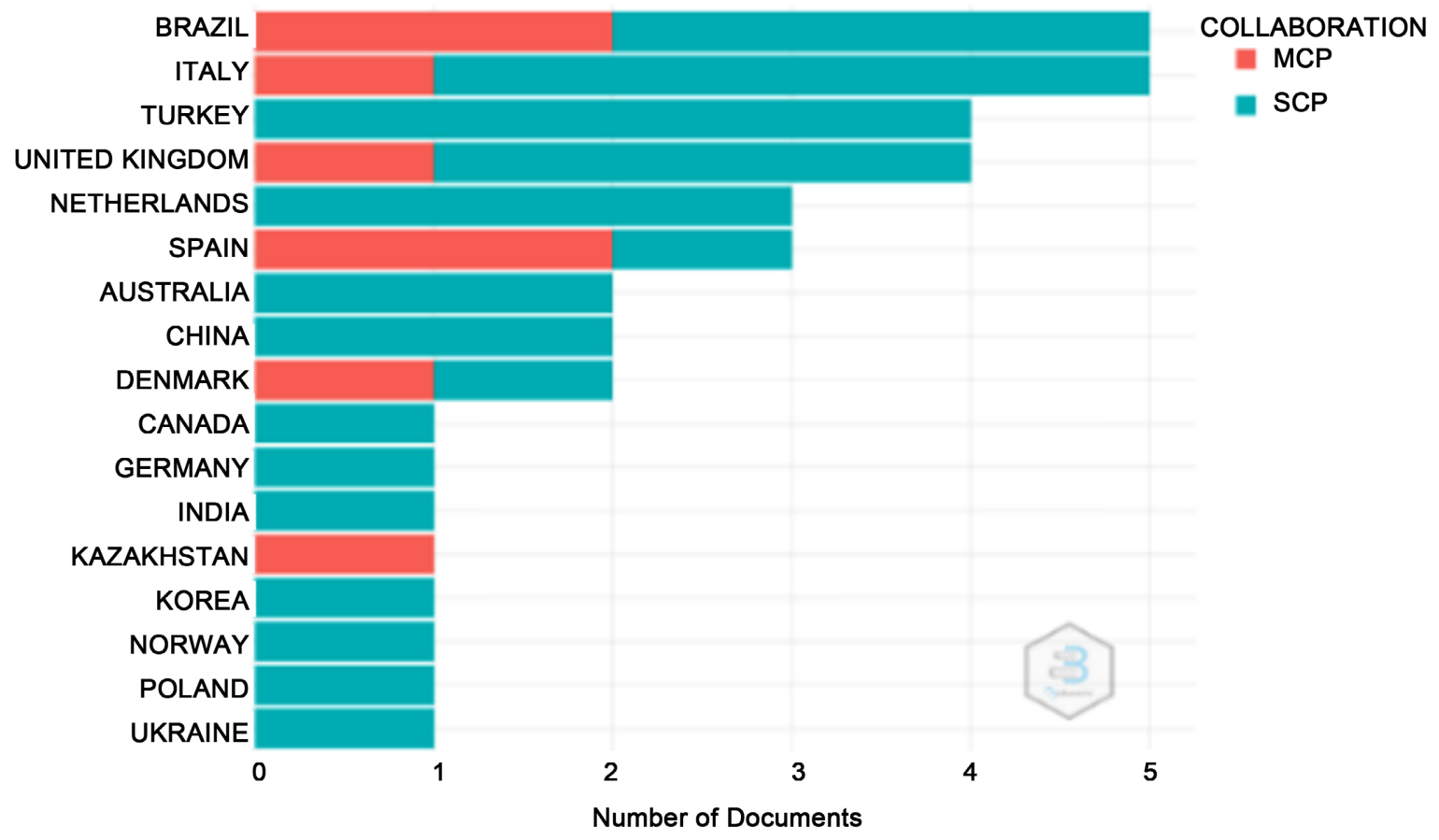

Figure 10. Most relevant countries by corresponding author. (SCP: Single Country Publications, MCP: Multiple Country Publications). (Source: own representation). 
Table 5. Most relevant countries by corresponding authors. (Source: own representation).

\begin{tabular}{|c|c|c|c|c|}
\hline Country & Freq & SCP & MCP & MCP Ratio \\
\hline Brazil & 0.1316 & 3 & 2 & 0.40 \\
\hline Italy & 0.1316 & 4 & 1 & 0.20 \\
\hline Turkey & 0.1053 & 4 & 0 & 0.00 \\
\hline United Kingdom & 0.1053 & 3 & 1 & 0.25 \\
\hline Netherlands & 0.0789 & 3 & 0 & 0.00 \\
\hline Spain & 0.0789 & 1 & 2 & 0.67 \\
\hline Australia & 0.0526 & 2 & 0 & 0.00 \\
\hline China & 0.0526 & 2 & 0 & 0.00 \\
\hline Denmark & 0.0526 & 1 & 1 & 0.50 \\
\hline Canada & 0.0263 & 1 & 0 & 0.00 \\
\hline Germany & 0.0263 & 1 & 0 & 0.00 \\
\hline India & 0.0263 & 1 & 0 & 0.00 \\
\hline Kazakhstan & 0.0263 & 0 & 1 & 1.00 \\
\hline Korea & 0.0263 & 1 & 0 & 0.00 \\
\hline Norway & 0.0263 & 1 & 0 & 0.00 \\
\hline Poland & 0.0263 & 1 & 0 & 0.00 \\
\hline Ukraine & 0.0263 & 1 & 0 & 0.00 \\
\hline
\end{tabular}

most relevant countries by corresponding authors nationalities. It shows the number of published papers in both Single Country Publications (SCP) and Multiple Country Publications (MCP). Brazil, Italy, and Turkey rank first with the largest number of papers. Documents published by SCP have a higher-trend productivity growth rate.

Table 6 depicts the most cited countries. Figure 11 illustrates their bibliographic coupling grouped in 3 clusters: CLUSTER 1: Canada, China, Denmark, Germany, Kazakhstan, Netherlands, Poland, South Korea, Spain, Turkey, United Kingdom; CLUSTER 2: Australia, Italy, Norway, Portugal, Sweden, CLUSTER 3: Brazil, United States. The citation analysis depicts the structure of the research area through the connections between countries. The timespan helps to explore the conceptual structures and analyze the evolution of themes over time. The collaboration networks show how countries relate to others in the research topic.

\subsection{Conceptual Structure-Co-Word Analysis}

This section describes the word treemap and the clusters of most popular keywords. Figure 12 below depict the co-word network visualization of the co-occurrence analysis based on author's keywords. The co-word networks describe the conceptual structure (i.e., the links between concepts) which characterizes the relationship between the keywords. The networks show the relationship among keywords within a document indicating themes or topics. Its node 
Table 6. Most cited countries. (Source: own representation).

\begin{tabular}{cccc}
\hline Country & Total citations & Documents & Total link strength \\
\hline Sweden & 566 & 3 & 17 \\
Denmark & 570 & 2 & 10 \\
Germany & 549 & 2 & 3 \\
France & 548 & 1 & 0 \\
Italy & 223 & 6 & 54 \\
Brazil & 171 & 6 & 52 \\
United Kingdom & 63 & 5 & 26 \\
Australia & 62 & 8 & 31 \\
Portugal & 51 & 2 & 25 \\
Norway & 48 & 3 & 22 \\
\hline
\end{tabular}

united states

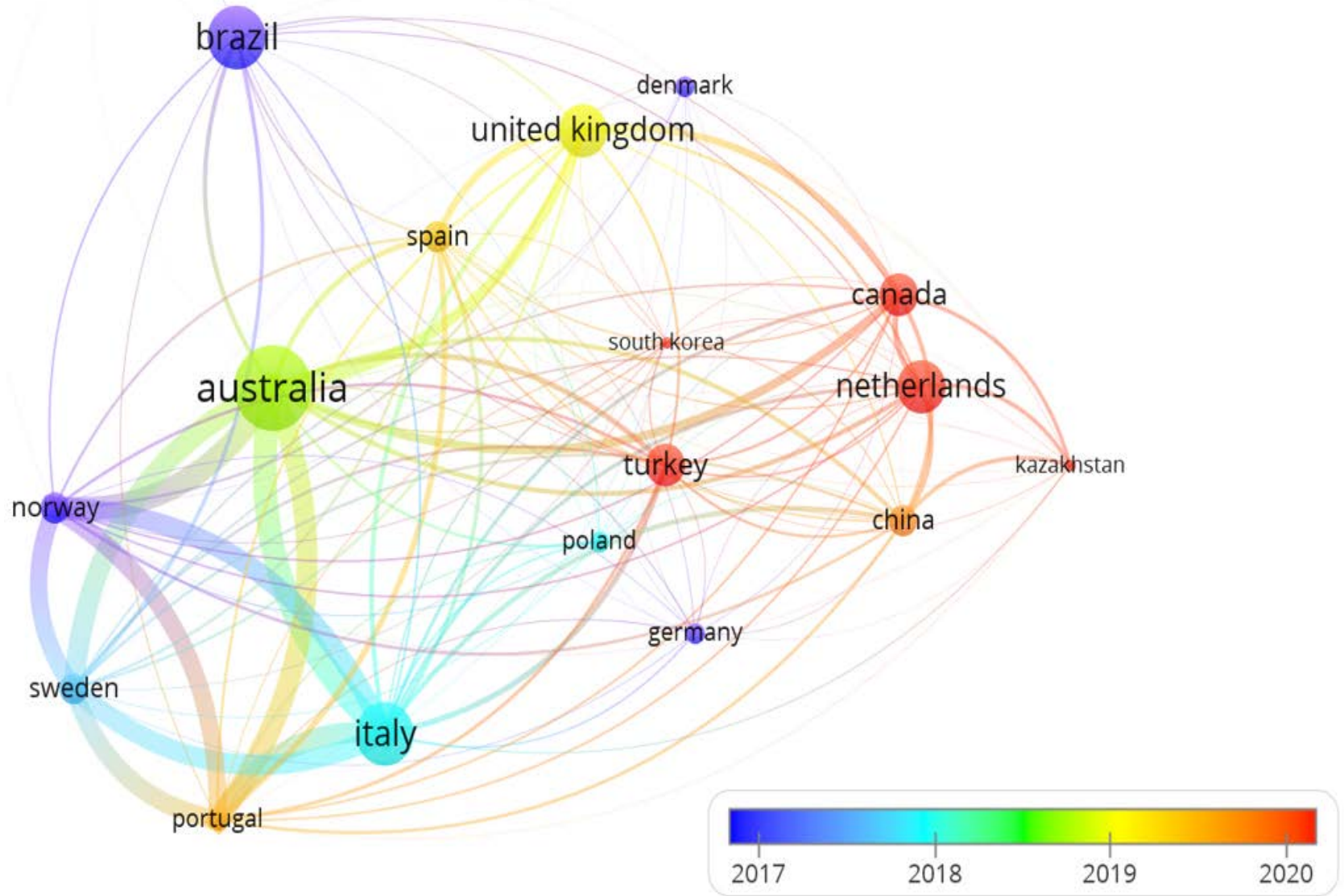

Figure 11. Bibliographic coupling of countries. (Source: own representation). 


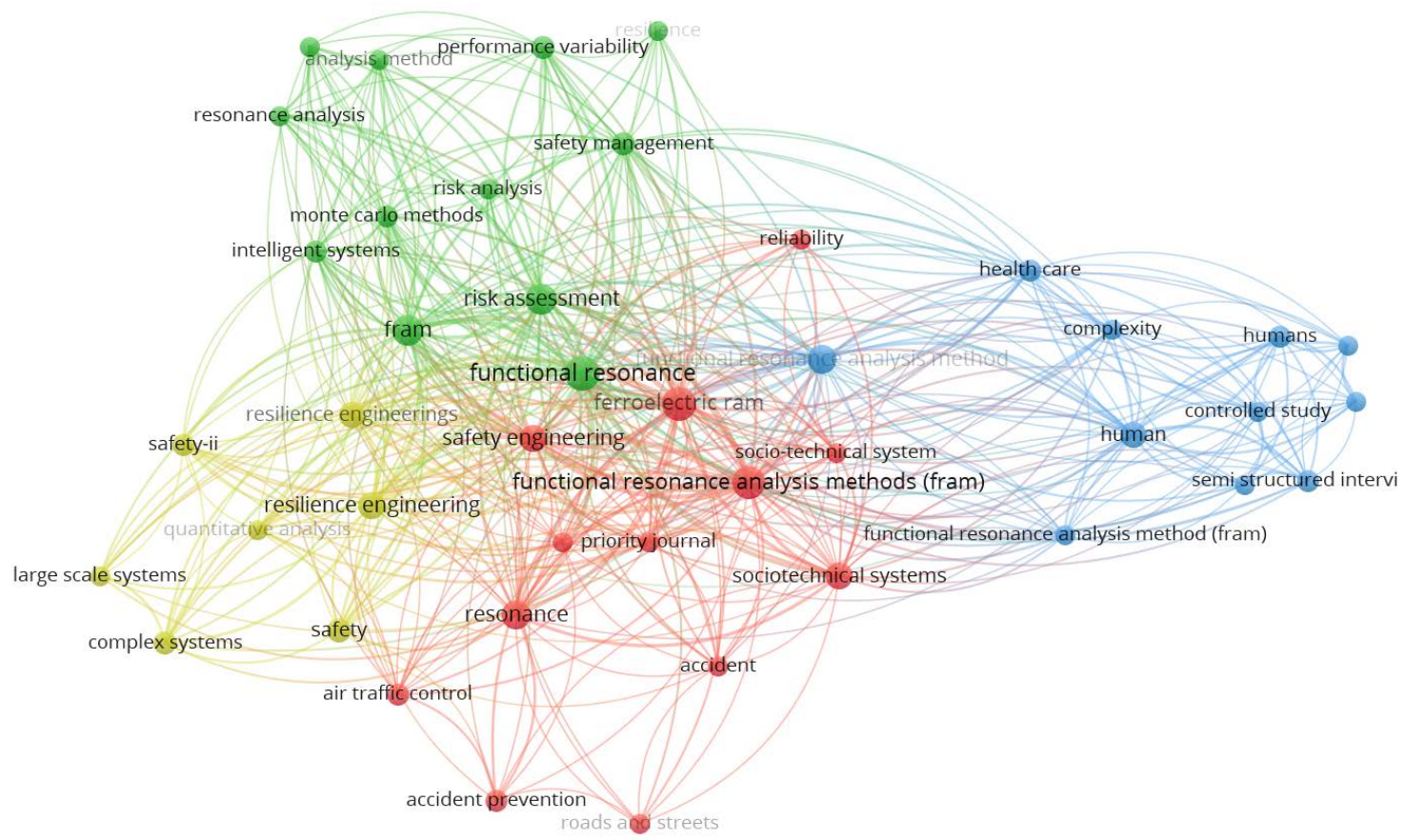

Figure 12. Network visualization of the co-word analysis through keyword co-occurrences. (Source: own representation).

corresponds to a keyword. Bigger is a link, greater is the relationship. This supports identify the intellectual domain of FRAM and provide research hotspots in this subject matter for future studies.

Information in Figure 13 and Figure 14 shows respectively the Tree-Map for the most pivotal Author's Keywords (DE) and Keywords Plus (ID) associated with FRAM analyses. The Word Tree-Map outlines hot themes or the dynamic trends of major themes of the author (Cobo et al., 2011). It is key to studying hot themes within the sphere of research.

The Three-Fields Plot is depicted in Figure 15 using the items: Country (AU_CO), Authors (AU) and Author's Keywords (DE). Appendix 1 shows the Three-Fields Plot for Keywords Plus (ID).

\subsection{Thematic Map}

Clusters identified through the co-word analysis above are deemed as themes that can be classified according to their density and centrality in a two-dimensional diagram (Cobo et al., 2011; Aria \& Cuccurullo, 2017). Themes can be analyzed according to the quadrant wherein they are positioned. Figure 16 depicts the thematic map encompassing seven clusters identified through the analysis of the centrality and density ranking of Keywords Plus. The cluster in the motor themes (first quadrant with the highest centrality and the highest density $)^{11}$ connoting that these themes is well-developed and significant for the

11 "The centrality is the degree of interaction of a network cluster in comparison with other clusters and gives information about the importance of a theme. The density measures the internal strength of a cluster network, and it can be assumed as a measure of the theme's development" (Aria \& Cuccurullo, 2017). 


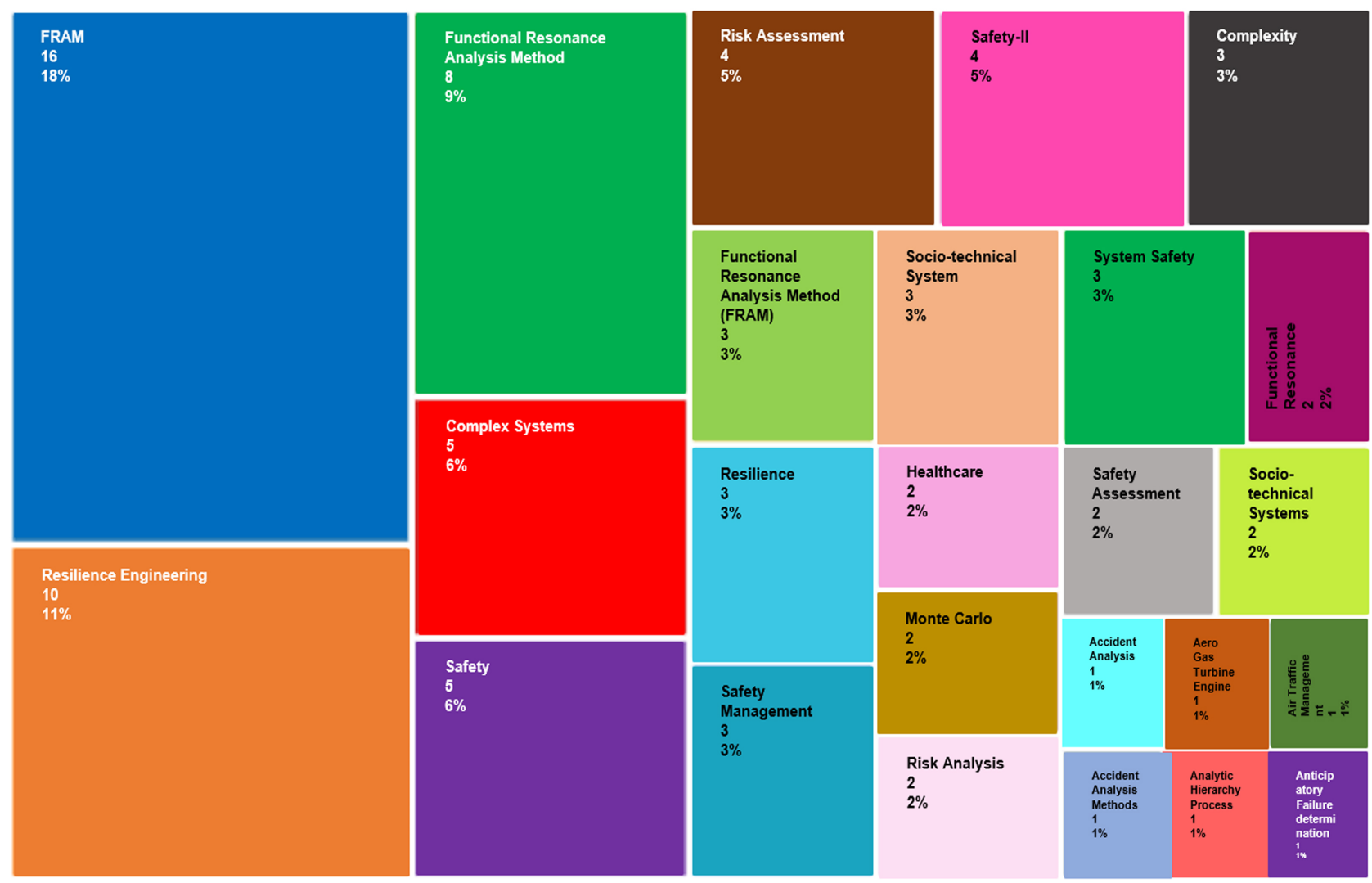

Figure 13. Tree-Map (Most relevant words (Author's Keywords)). (Source: own representation).

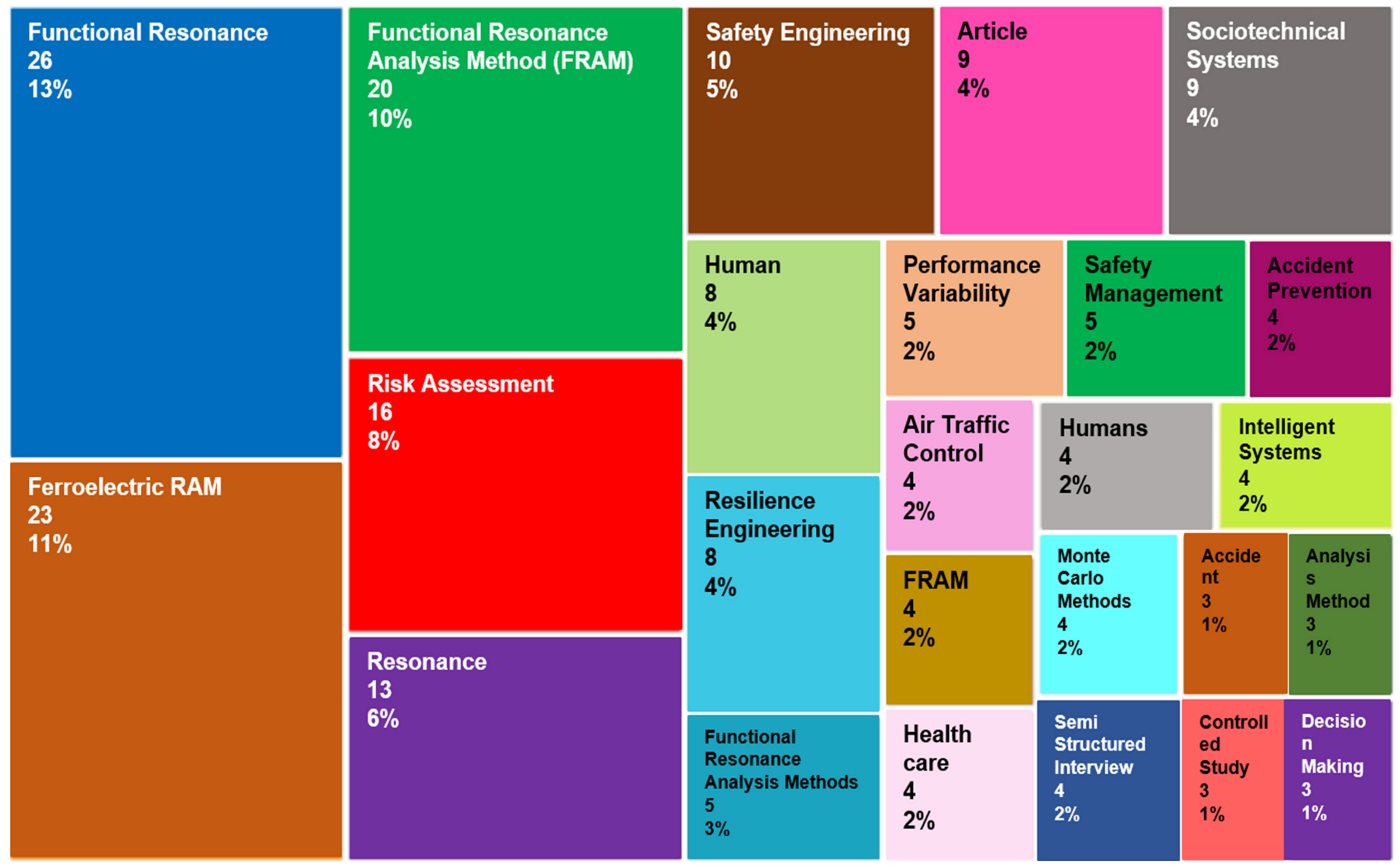

Figure 14. Tree-Map (Most relevant words (Keywords Plus)). (Source: own representation). 


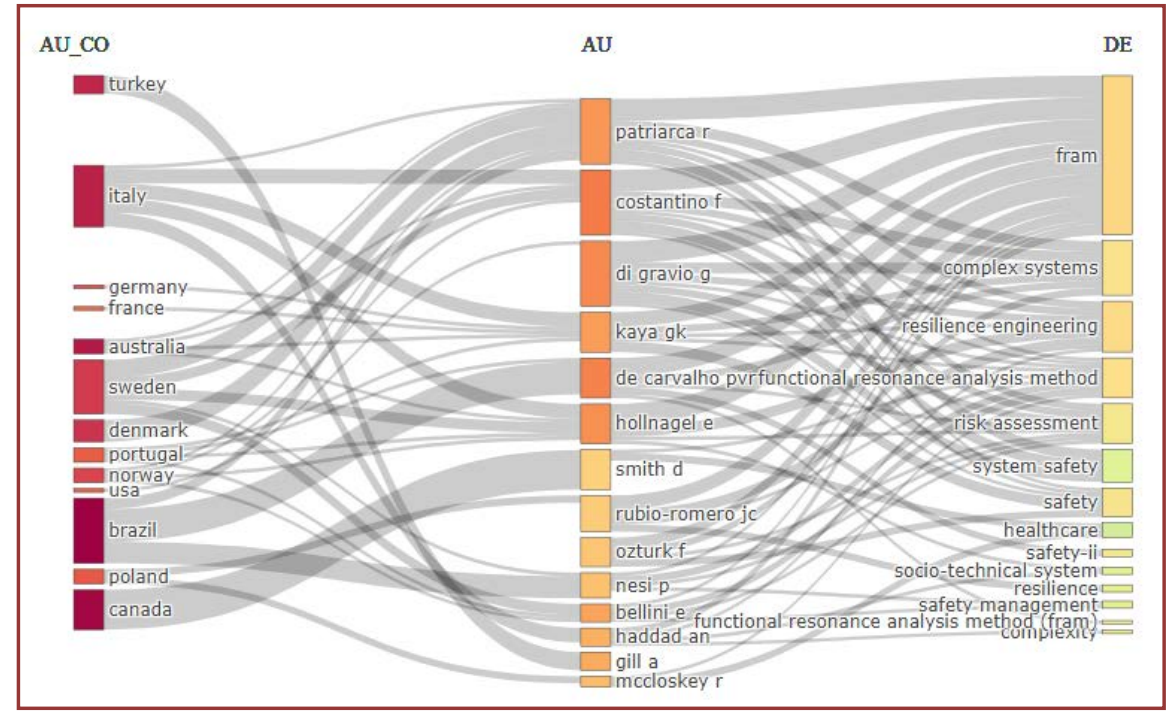

Figure 15. Three-Fields Plot: Country (AU_CO), Authors (AU), Keywords (DE). (Source: own representation).

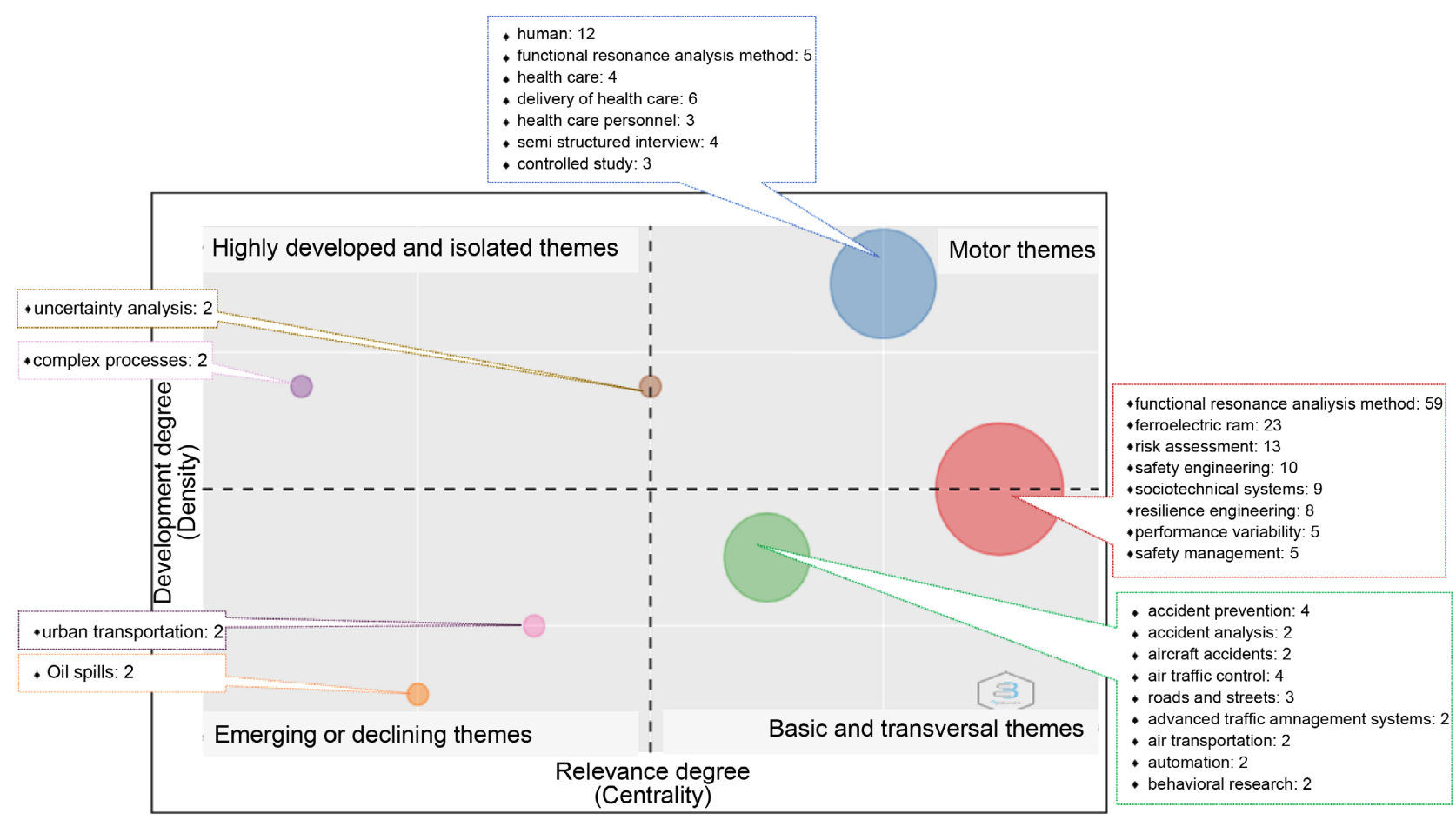

Figure 16. Thematic map displaying clusters and Keywords Plus. (Source: own representation).

shaping of the research area. It contains Keywords Plus "human", "functional resonance analysis method", "health care", "delivery of health care", "health care personnep", "semi structured interview", and "controlled study" as the most co-occurring words. The cluster straddling between the motor themes and the basic themes, with a good centrality and density, includes words: "functional resonance analysis method", "ferroelectric ram", "risk assessment", "safety engineering", "sociotechnical systems", "resilience engineering", "performance va- 
riability", "safety management" being the most recurring words. The cluster in the highly developed and isolated themes or niche themes (second quadrant with low centrality and high density) includes the single word "complex processes" implying that it has low reputation for the subject matter. The two clusters in the emerging or declining themes denoting they are weakly studied(third quadrant with low centrality and low density) encompasses words "oil spills", "urban transportation" as the most repetitive words. The cluster in the basic and transversal themes relating to general and various research areas (fourth quadrant with high centrality and low density) incorporates words "accident prevention", "accident analysis", "aircraft accidents", "air traffic controp", "roads and streets", "advanced traffic management systems", "air transportation", "automation", "behavioral research". Lastly, the cluster straddling between the motor themes and the highly developed and isolated themes, with a good centrality and high density, includes the only word: "uncertainty analysis".

\section{Discussion}

The study carried out a comprehensive bibliometric literature review of the application of the functional resonance analysis method (FRAM) intended for the assessment of performance variability in complex and dynamic socio-technical systems. The following paragraphs discuss the FRAM approach and some of its limitations. We also carry out a comparison of different assessment methods and the FRAM tool.

\subsection{The FRAM Approach}

There is a rising appeal in utilizing the FRAM methodology for the assessment of what precisely is happening in complex and dynamic socio-technical systems in practical high hazard environments (for e.g.: de Vries, 2017; De Carvalho, 2011; Adriaensen et al., 2019; Aguilera et al., 2016; Albery et al., 2016; Anvarifar et al., 2017; Belmonte et al., 2011; Bjerga et al., 2016; Buikstra et al., 2020; Clay-Williams et al., 2015; Costantino et al., 2018; Duan et al., 2015; Falegnami et al., 2019; Praetorius et al., 2015; Ferreira \& Cañas, 2019; França et al., 2019; Gattola et al., 2018; Smith et al., 2020; Jensen \& Aven, 2017; Furniss et al., 2016; Gao et al., 2019). The FRAM is a relatively new performance appraisal tool for risk assessment or accident investigation, in line with the thinking of the resilience engineering (RE) and reflects the "Safety II" theory rather than the traditional "Safety I" theory toward everyday operations or "events" (Hollnagel, 2012, 2014). The "Safety I" thinking (such as in Failure Mode and Effects Analysis, FMEA) focuses on what goes wrong (how a component may fail), while the "Safety II" thinking concentrates on what goes right (define the functions that are mandatory for the system to attain its objective). The FRAM approach enables practitioners to describe a complex and dynamic socio-technical system in the matter of the functions and the interactions among functions forming this system. Thus, performance variability can be investigated to understand where it may occur then disseminate all over the system (functional resonance) i.e., in 
what manner functional variability can deteriorate into unforeseen and undesirable outcomes. The RE, an attitude that has constantly advocated that safety is beyond the absence of failures, tackles how the socio-technical system may adjust to withstand disturbance within the mandatory parameters then maintain performance in required parameters (for e.g., Cabrera et al., 2014).

The outcomes of "how functions become coupled" and how "everyday performance variability may resonate" are the main objectives of the FRAM approach. The latter is a method rather than a model (Hollnagel, 2012). Accordingly, it neither formulates hypotheses about potential causes and cause/consequence relationships nor regarding how the system under probe is organized or structured. It is based on four comprehensive principles in line with the RE approach, namely:

- the principle of equivalence of success and failure ${ }^{12}$,

- the principle of approximate adjustments ${ }^{13}$,

- the principle of emergence ${ }^{14}$,

- the principle of functional resonance ${ }^{15}$.

Figure 17 describes the four core steps of the FRAM approach (Hollnagel, 2012).

First and foremost, Step 0 (preliminaries) is a requirement for defining the

12" Equivalence of successes and failures. Whenever something is done, the intention is always to do something right and never to do something wrong. For each action, the choice of what to do is determined by many different things, including competence, understanding of the situation, experience, habit, demands, available resources, and expectations about how the situation may develop not least about what others may do. If the expected outcome is obtained, the next action is taken, and so on. But if the outcome is unexpected, then the preceding action is re-evaluated and classified as wrong rather than right, as an error or as a mistake, using the common but fallacious post hoc ergo propter hoc argument. With hindsight, it is pointed out what should have been done, if only people had made the necessary effort at the time. The whole argument is, however, unreasonable because the action was chosen based on the expected rather than the actual outcome. Failures and successes are equivalent in the sense that we can only say whether the preceding action was right or wrong after the outcome is known. That changes the judgement of the action, but not the action itself” (Hollnagel, 2016).

${ }^{13}$ "Approximate adjustments. When working conditions are underspecified or when time or resources are limited, it is necessary to adjust performance to match the conditions. This is a main reason for performance variability. But the very conditions that make performance adjustments necessary also mean that the adjustments will be approximate rather than perfect. The approximations are, however, under most conditions good enough to ensure successful performance" (Hollnagel, 2016).

${ }^{14}$ Emergence: the meaning of emergence is not that something happened "magically", but simply that it happens in such a way that it cannot be explained using the principles of decomposition and causality (Hollnagel, 2016).

15“Resonance: In physical systems, classical (or mechanical) resonance refers to the phenomenon that a system can oscillate with larger amplitude at some frequencies than at others. These are known as the system's resonant (or resonance) frequencies. At these frequencies even small external forces that are applied repeatedly can produce large amplitude oscillations, which may seriously damage or even destroy the system. "Functional resonance is defined as the detectable signal that emerges from the unintended interaction of the everyday variability of multiple signals. The signals are usually subliminal, both the 'target' signal and the combination of the remaining signals that constitutes the noise. But the variability of the signals is subject to certain regularities that are characteristic for different types of functions, hence not random or stochastic. Since the resonance effects are a consequence of the ways in which the system functions, the phenomenon is called functional resonance rather than stochastic resonance" (Hollnagel, 2016). 


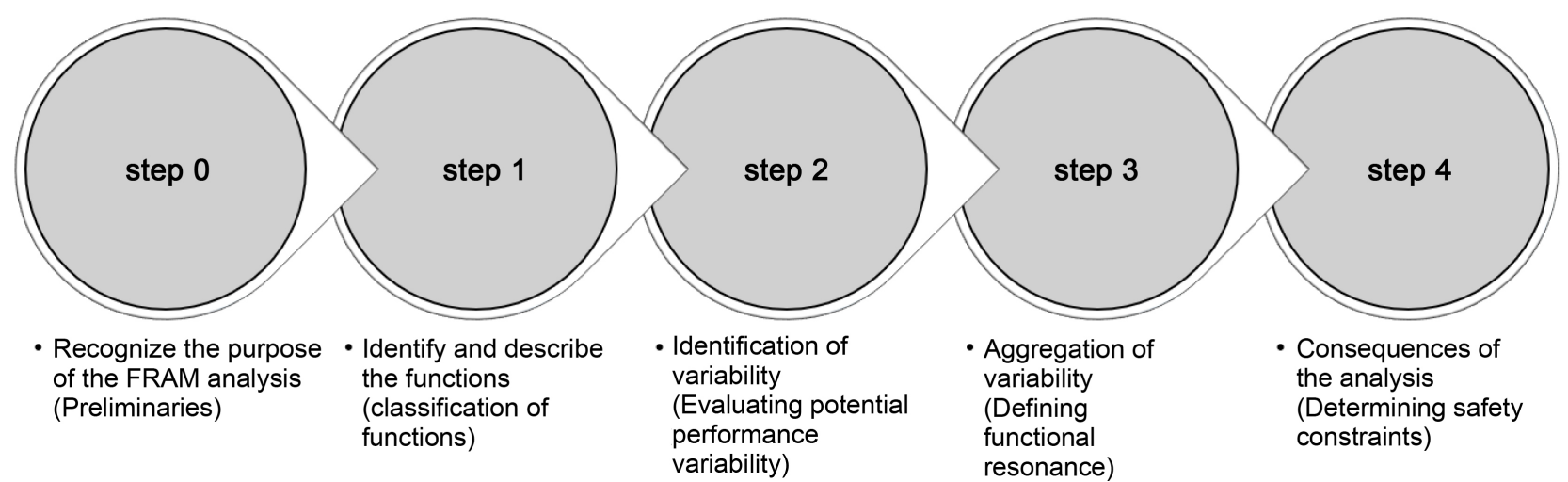

Figure 17. Main steps of the FRAM approach. (Source: own representation based on Hollnagel (2012)).

analysis objective. Two analyses purposes are possible: 1) risk assessment (system descriptions, for e.g. Rosa et al., 2015) or 2) accident investigation (probe of the causes of the accident and draw the relevant conclusions, for e.g. De Carvalho, 2011; Herrera \& Woltjer, 2010).

The first step (Step 1: Identify and Describe the Functions) focuses on identifying the functions (i.e. activities or set of activities) that are required for a given system or organisation to produce a certain outcome. Functions may be accomplished by technological systems or human operators, individually or cooperatively. Six aspects, namely Intput (I), Output (O), Preconditions (P), Recourses (R), Time (T), Control IC), describe a function as illustrated graphically by a hexagon in Figure 18. Thus, activities are identified, described and classified in term of how they are accomplished everyday rather than how they are imagined, facilitating to enhance insight of how variability may arise and propagate. Functions are classified either foreground, i.e., functions whose variability might influence the result of the assessment, or background, i.e., functions that are relatively stable and have less influence on the result of the assessment. Function-coupling is characterized as the interaction among functions. Function can be upstream (arising before another one) or downstream (arising after another one). This requires appropriate acknowledgement of the system.

The second step (Step 2: identification of variability) characterizes both the potential variability and the expected actual variability of the functions to determine the variation in the functional output instead of the change in the function. The potential variability refers to the model, while the expected actual variability refers to an instantiation of the model ("the FRAM model represents the set of functions that together account for the activity being analysed and the potential couplings among functions. An instantiation describes the couplings that existed or may exist for a given scenario or a set of conditions, and thus represents a realisation of the model' (Hollnagel, 2012)). This determines how each individual function can be influenced by internal (endogenous) or external (exogenous) performance variability.

The third step (Step 3: aggregation of variability) focuses on the combination of variability (i.e., functional resonance). It supports to identify which functions 


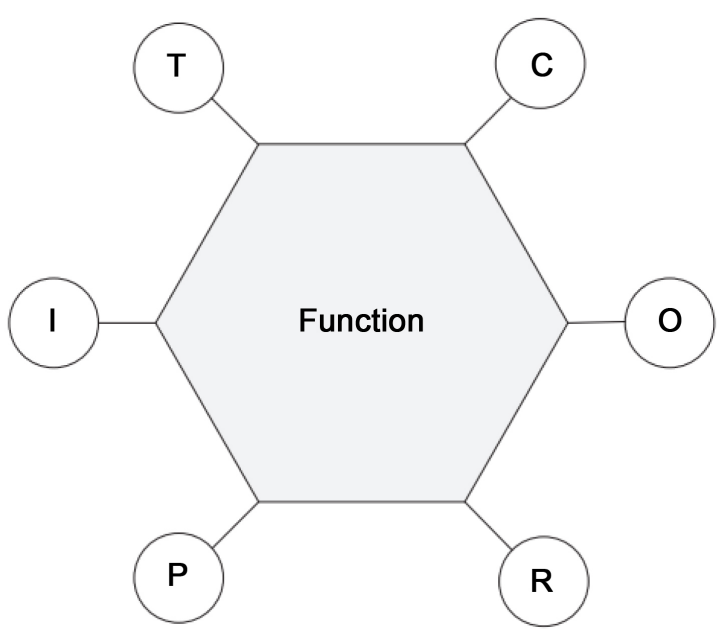

\begin{tabular}{|c|l|l|}
\hline I & Input & $\begin{array}{l}\text { that which the function processes or transforms or that which starts } \\
\text { the function }\end{array}$ \\
\hline O & Output & $\begin{array}{l}\text { that which is the result of the function, either an entity or a stage } \\
\text { change }\end{array}$ \\
\hline $\mathrm{P}$ & Preconditions & conditions that must be exist before a function can be carried out \\
\hline $\mathrm{R}$ & Recourses & $\begin{array}{l}\text { that which the function needs when it is carried out (Execution } \\
\text { Condition) or consumes to produce the output }\end{array}$ \\
\hline $\mathrm{T}$ & Time & $\begin{array}{l}\text { temporal constraints affecting the function (about starting time, } \\
\text { finishing time or duration) }\end{array}$ \\
\hline $\mathrm{C}$ & Control & how the function is monitored or controlled \\
\hline
\end{tabular}

Figure 18. Representation of a function in FRAM. (Source: (Hollnagel, 2012)).

may encounter potential performance variability and how the outcome may spread through the system. Once the functions are coupled, the interaction among them comes to be evident. The potential variability appraisal enables to recognize how upstream function variations impact downstream functions by up-down coupling. Thus, the true interest of the evaluation is to grasp the variation in the outcome of the function more willingly than the variation in the function itself; ("since a FRAM model does not stand for any specific situation, it can only represent the potential performance variability. The range of this can be estimated based on established scientific knowledge as well as practical experience from a domain. An instantiation represents a concrete instance of the model for given (actual or assumed) circumstances and set( $s$ ) of conditions, and the details provided by the instantiation makes it possible to be more precise about whether and how the potential variability can become actual variability. It is, however, not enough to know what the actual variability may be for individual functions. It is also necessary to know how variability may combine and thereby lead to outcomes that are either unexpected or out of scale-or both. In other words, it is necessary to know how functional resonance can come about. This is done by using the idea of function upstream-downstream coupling" (Hollnagel, 2012)). 
The fourth step (Step 4: consequences of the analysis) aims at managing and controlling performance variability as well as encouraging effective outcomes (rather than only weakening undesirable outcomes). As soon as unforeseen or unwanted outcomes arise, safety measures should allow useful actions to be taken. In addition to the well-established methods such as safety prevention (barriers or defense), eliminating the hazards at the source if known, protection, etc., the FRAM methodology recommends two further solutions, namely monitoring (performance indicators) and dampening, in line with the four principles of underlying the FRAM. Therefore, the answer is to manage performance variability, typically by attempting to dampen the variability in order to diminish resonance influences (Hollnagel, 2012).

The RE and the FRAM idea recognize that things succeed and fail in fundamentally the similar way (i.e., the equivalence of successes and failures). The Principle of Approximate Adjustments means that adjustments are omnipresent and beneficial. This principle elucidates why resources like workforce, time, information, are not infinite and require recurrent approximate adjustments rather than exact. Indeed, organizations recurrently adapt and adjust their performance ${ }^{16}$. For e.g., an organization setting of objectives and priorities as well as actions to be undertaken against uncertainties of the environment such as supervisory requirements and legal liabilities, challenges of talents acquisition and their retention in the workplace, uncertainty in worldwide markets deregulation, technological innovation and technological obsolescence, constantly rising customer demands. Likewise, challenges are the current uncertain business context caused by the coronavirus disease pandemic, natural disasters, terrorist attacks and major cyberattacks (Diop et al., 2021). Subsequently, numerous socio-technical systems are problematic. The occupational conditions never entirely agree with what has been predetermined or suggested. The subsequent performance variability is the explanation why things either succeed or fail. However, the explanations that make the adjustments essential also imply that they are approximate rather than exact. The reason why things generally succeed or sometimes fail is attributable to approximate adjustments. In other words, outright failures, malfunctioning or errors for instance, do not mostly cause things to go wrong. Instead, the daily performance variabilities sum up or combine in an unforeseen way (i.e., the principle of functional resonance) causing something to fail. On one hand, normal performance variabilities hardly lead to possible safety concerns or failures since many of them are rarely significant to be the cause of mishaps or breakdowns, but on the other hand, despite actions

\footnotetext{
${ }^{16}$ Performance variability: The study of risk and accidents has traditionally focused on how failures or malfunctions of components or elements (technological, human, organisational) could happen and how the effects could propagate through the system. This can be called a bimodal view of functions and performance. The FRAM is based on the principle of equivalence of successes and failures and the principle of approximate adjustments. Performance is therefore in practice always variable. The performance variability of upstream functions may affect the performance variability of downstream functions, and thereby lead to non-linear effects (functional resonance). (A FRAM Glossary https://functionalresonance.com/a-fram-glossary.html).
} 
Table 7. Alternative risk assessment techniques compared to FRAM (Source: own representation). (Abbreviation in the Table 7: QL: Qualitative approach. QT: Quantitative. P: Proactive approach. R: Reactive approach).

\begin{tabular}{|c|c|c|c|c|}
\hline Methods & Description & Application & QL/QT & $\mathrm{P} / \mathrm{R}$ \\
\hline  & $\begin{array}{l}\text { The FRAM investigates how occupational activities } \\
\text { occur retrospectively ("analyses of accidents or } \\
\text { events") or prospectively ("analyses of current } \\
\text { work domain or envisioned scenarios for risk } \\
\text { management", etc.) by examining work activities } \\
\text { with the purpose of understanding how work } \\
\text { is accomplished everyday and how things } \\
\text { turned wrong or right (Hollnagel, 2012; } \\
\text { Patriarca et al., 2020). } \\
\text { - It is relevant for modelling and interpreting } \\
\text { complex systems. It highlights complexity in } \\
\text { the functions, and various circumstantial } \\
\text { changes that may influence system } \\
\text { performance. It offers better understanding } \\
\text { of the system as a whole. } \\
\text { - However, this method lacks numerical } \\
\text { aspects involved in the methodology utilized } \\
\text { to build the model. It is not appropriate } \\
\text { for use in particular areas such as sensitivity } \\
\text { analysis. The couplings between the } \\
\text { functions can be complex. The FRAM } \\
\text { is a time-consuming process. } \\
\text { In some case, FRAM could be combined with } \\
\text { other methods such as FMEA to be useful } \\
\text { (Melanson \& Nadeau, 2019). }\end{array}$ & $\begin{array}{l}\text { Various high-risk fields such as: } \\
\text { - } \quad \text { Nuclear Power } \\
\text { - } \quad \text { Aircraft De-icing } \\
\text { - } \quad \text { Air Traffic Management } \\
\quad \text { Safety Assessment } \\
\text { - } \quad \text { Health Care } \\
\text { - } \quad \text { Railway Traffic } \\
\text { - } \quad \text { Maritime Mining } \\
\text { - } \quad \text { Maritime Transportation } \\
\text { - } \quad \text { etc. } \\
\text { For e.g., Hollnagel, 2012; Hollnagel, } \\
\text { Woods, \& Leveson, 2012; Hollnagel, } \\
\text { 2018; Hollnagel et al., 2014; } \\
\text { Hounsgaard, 2016; Huang et al., } \\
\text { 2019; Lee \& Chung, 2018; Macchi, } \\
\text { 2010; Nemeth \& Hollnagel, 2016; } \\
\text { Slater et al., 2022; Slim, 2020. }\end{array}$ & QL & $\mathrm{P}, \mathrm{R}$ \\
\hline 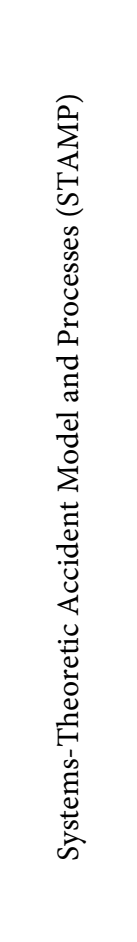 & $\begin{array}{l}\text { The STAMP is an accident causality model proposed } \\
\text { by Leveson (2016). } \\
\text { - It is a systemic approach to safety analysis } \\
\text { (Allison et al., 2017; Leveson, 2004), centered on } \\
\text { negative effects and countermeasures (Patriarca } \\
\text { et al., 2020; Ferjencik, 2011). For e.g., Ferjencik, } \\
\text { 2011; Ouyang et al., 2010. The STAMP method } \\
\text { describes "how complex systems are dynamic and } \\
\text { migrate towards accidents due to physical, } \\
\text { social and economic pressures, rather than } \\
\text { sudden loss of control capacity" (Salmon et al., } \\
\text { 2012). The STAMP encompasses an } \\
\text { analytical risk assessment method, } \\
\text { namely: the System-Theoretic } \\
\text { Process Analysis (STPA). } \\
\text { However, Leveson (2016) indicates that this } \\
\text { method is not designed for one looking for } \\
\text { someone to blame (Leveson, 2016; Allison } \\
\text { et al., 2017), nevertheless, it can offer, at a } \\
\text { system level, information about the } \\
\text { adjustment considered necessary to avoid, } \\
\text { or reduce the effect of mishaps in the future. }\end{array}$ & $\begin{array}{l}\text { Appropriate for complex systems } \\
\text { such as: } \\
\text { - } \text { Software } \\
\text { - } \text { Space, Aviation } \\
\text { - Human Factors } \\
\text { - } \text { Organizational Design } \\
\text { - } \text { Medical } \\
\text { - } \text { Defense, } \\
\text { - Nuclear, } \\
\text { - } \quad \text { etc. } \\
\text { For e.g., Allison et al., } 2017 .\end{array}$ & QL & $\mathrm{P}, \mathrm{R}$ \\
\hline
\end{tabular}




\section{Continued}

FMECA is an extension of the inductive analytical method

FMEA by incorporating a criticality assessment. These

bottom-up processes help identify, prioritize, then act on

likely failure modes. They offer a listing of all potential

failure modes and causes. Each breakdown mode is assessed for its criticality then interpreted in term

of risk (Dai et al., 2011).

- It is relevant for identifying hazards and circumstances that can be used as drivers for system changes, in contrast to the FRAM which is more appropriate to model and understand complex systems or processes (Patriarca et al., 2020; Das et al., 2018).

- However, the FMEA process is simply as good as the subject matter experts behind the analysis in question. Many failure modes might be missed. It is a time-consuming process; it should be consistently revised as new prospective failure modes are identified.

- It does not consider combined failures and human concerns. Combining FMEA with FRAM or used in conjunction with other methods may possibly be beneficial (Melanson \& Nadeau, 2019; Das et al., 2018; Sujan \& Felici, 2012).

This method helps identify the set of multiple causes (underlying root causes) of a failure in order to identify suitable solutions to prevent the problem from arising again.

- For e.g., Management Oversight and Risk Tree (MORT) analysis (an analytical method for defining causes and contributing factors.) (Rasmussen et al., 1994; Johnson, 1973).

- However, in contrast to the FRAM, The RCA does not offer a better insight of the complexity in the processes and the couplings contained by the work settings; it might exist more than one root cause to a malfunction (Patriarca et al., 2020; Alm \& Woltjer, 2010; Nakajima, 2017).

This top-down method, based on deductive reasoning (deductive logic), help analyze undesired state of a system (failures, malfunctions) utilizing Boolean logic.

- It supports effective decision-making in identifying root failure modes and identify likely failure causes for the root failure modes (Dai et al., 2011).

- It might be useful to combine the FTA and the FRAM process (Toroody et al., 2016). However, the FTA may not be suitable for some complex and dynamic socio-technical systems such as human-centric maritime operations (Patriarca et al., 2020; Toroody et al., 2016; Praetorius \& Kataria, 2016).

Numerous fields such as:

- risk management tool in nuclear industry

- IT

- Industrial process control

- Accident analysis

- Telecommunications

- etc.

For e.g., Appicharla, 2011; Alm \& Woltjer, 2010; Nakajima, 2017.

Various high-hazard industries such as:

- Nuclear power

- Chemical and process

- Aerospace

- Petrochemical

- Software engineering

- Pharmaceutical

For e.g., Toroody et al., 2016;

QL, QT P
QL, QT P

Praetorius \& Kataria, 2016; Goldberg et al., 1994; Center for Chemical Process Safety, 2008; Center for Chemical Process Safety, 1999; U.S. Department of Labor Occupational Safety and Health Administration Process, 1994; Lacey, 2011. 


\section{Continued}

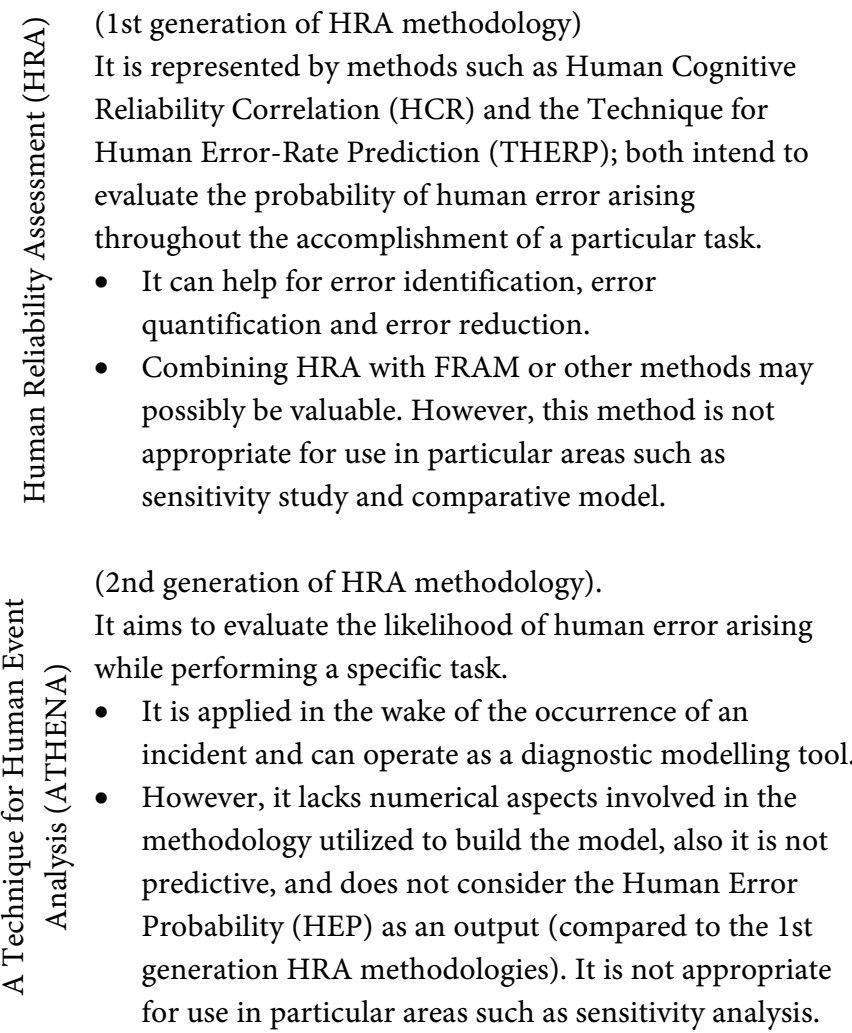

Numerous fields such as:

- Manufacturing

- Medicine

- Nuclear power

- etc.

Various fields such as:

- Healthcare

- Engineering

- Nuclear

QT, QL R

- Transportation

- etc.

Fields such as:

- Healthcare

- Manufacturing

QL $\quad$ P

- Transportation

- etc.

To assess accident in various sectors such as:

- Mining

- Bushfire

QL $\quad$ R

- Transportation

- etc. analysis and formulate safety recommendations. It might be useful to combine the AcciMap, the FRAM process and STAMP (Yousefi et al., 2019). 


\section{Continued}

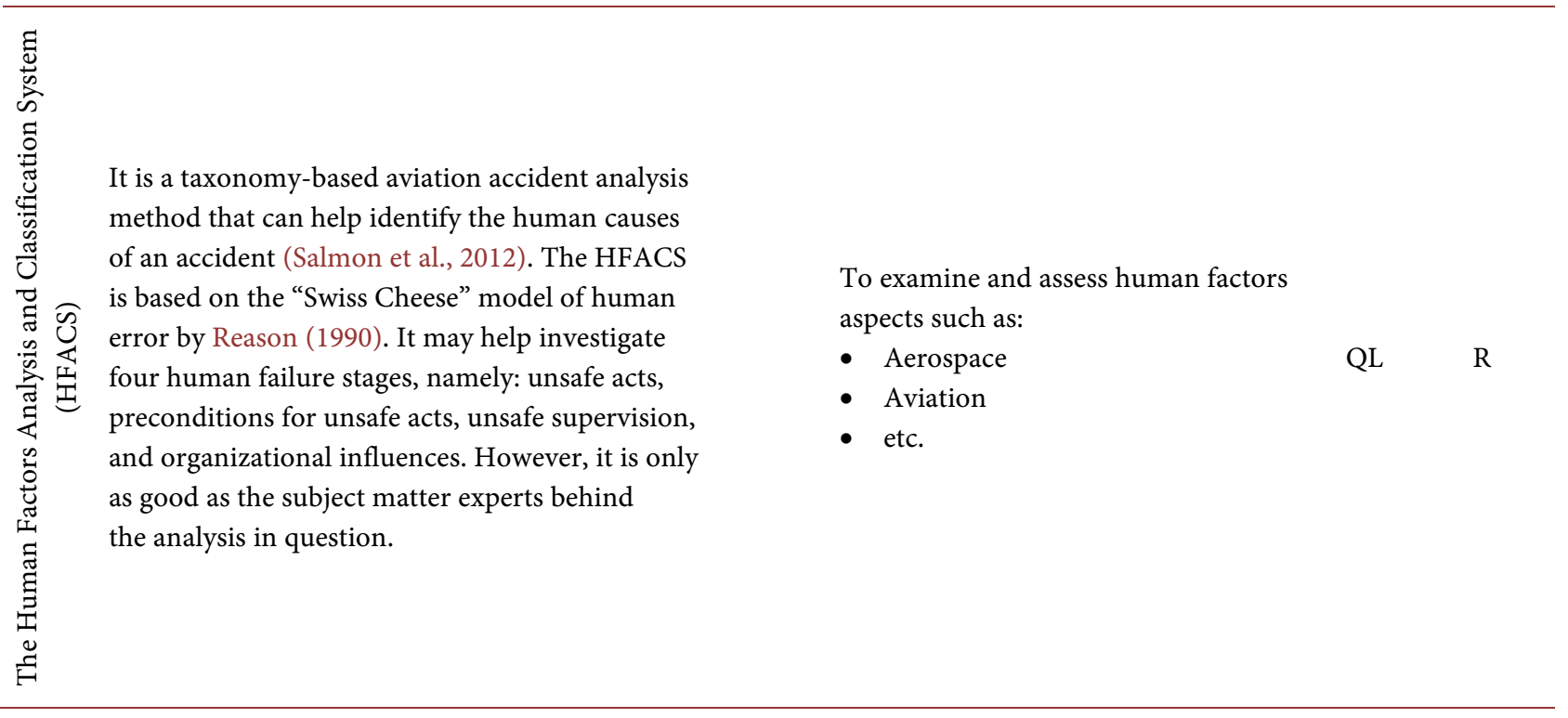

taken up to now, countless tragedies and human lives losses still occur every single day. For instance, recent disasters such as the deadly explosion in 2020, during test operations of Fortesa's Gadiaga-2 Gas Field located in the village of Gadiaga, north of Dakar in Senegal, actualize the issue of onshore and offshore safety. A vicious fire broke out at one of the wells of the gas field operated by Fortesa International (AODL: Africa Onshore Drilling LTD). Likewise, for e.g., the MV Le Joola disaster, the second-worst non-military tragedy in maritime history. This roll-on/roll-off ferry was belonging to the Senegalese government. It capsized off in 2002 with 1863 losses in human life and 64 survivors.

These consequences can be explained by the combination in unexpected manners of multiple functions performance variability. Indeed, both normal performance and failures are emergent instead of the outcome of events or phenomena (i.e., the principle of emergence). In fact, risk should be seen as a developing attribute of complex and dynamic socio-technical systems. Therefore, it is urgent to investigate thoroughly at these kinds of disturbance to fully grasp all the connotations and ascertain the real needs that call for a response at strategic level.

\subsection{Other Assessment Approaches as an Alternative or Complementary Method to the FRAM Process}

This section carries out an evaluation of some of the most established methods used for risk assessment and management that may constitute an alternative or a complementary method to the FRAM process namely, the AcciMap, the Systems-Theoretic Accident Model and Processes (STAMP), the Management Oversight and Risk Tree (MORT), the Failure Mode and Effect Analysis (FMEA), the Root-Cause Analysis (RCA), the Human Reliability Assessment (HRA). Table 7 depicts these non-exhaustive assessment processes. 


\section{Conclusion and Future Research}

The unstable economic context is forcing organizations to adapt their economic models to contend with the challenges inflicted by the fierce competition of international markets (Diop et al., 2019). Companies that fully understand and grasp the value of the benefits that emanate from digital maturity including industry 4.0 technologies will be best positioned to meet the challenges of the future (Diop et al., 2021). However, over the last decades, occupational environment has become progressively more complex due to the arrival of the four industrial revolutions, namely industry 4.0. These organizations face significant uncertainties and dreaded risks of all kinds such occupational health and safety in safety critical domains.

Both scholars and practitioners have been interested in the application of the functional resonance analysis method (FRAM) in support of the assessment of performance variability in complex and dynamic socio-technical systems. A growing trend of publications on this subject matter is obvious in our bibliometric literature review. Hence, the metrics show a substantial increase of the number of scholars and countries involved in this area of research. The outcomes of this survey showed the usefulness of the FRAM methodology for systemic safety assessment to explain performance variability. There are many challenging projects in this research area calling for responses, for e.g., supply chain sustainability in the context of COVID-19 pandemic, the challenges of onshore and offshore safety, the challenges for healthcare in a context of pandemic response, aviation safety, electrical utilities such as transmission and distribution which are considered as capital-intensive assets and complex adaptive system of systems (in line with theme 3 of the Hydro-Québec asset management chair $)^{17}$. For e.g., Hydro-Québec has substantial asset portfolios. Abdul-Nour et al. (2021) noted that "in every step of the chain of production, electrical utilities must know the condition, location and availability of their assets to maximize productivity, reduce service interruptions and ensure the safety of operations and users". Therefore, it is crucial to look thoroughly at this methodology to grasp all the recommendations and identify the real demands that call for an answer at the strategic level. Abdul-Nour et al. (2021) proposed a resilience management framework designed for complex systems as sown in Figure 19. In this regard, five components, namely: 1) "scientific evidence, 2) knowledge bases, 3) global assessment of risks, 4) review and judgment of management, and 5) decision making", form the decision-making process in relation to risks.

The outcome of this review contributes to legitimize and validate the FRAM process for describing sociotechnical work inside the immense discipline of safety assessment and physical asset management. It also emphasises some pros and cons of this process. Accordingly, other assessment approaches were presented as a complement or an alternative to the FRAM process.

\footnotetext{
${ }^{17}$ Theme 3: "Modelling the risks of extreme events and external factors in complex asset management: Objective. Developing a global methodology for modelling the impact of extreme or rare events and external factors on the asset management strategy".
} 


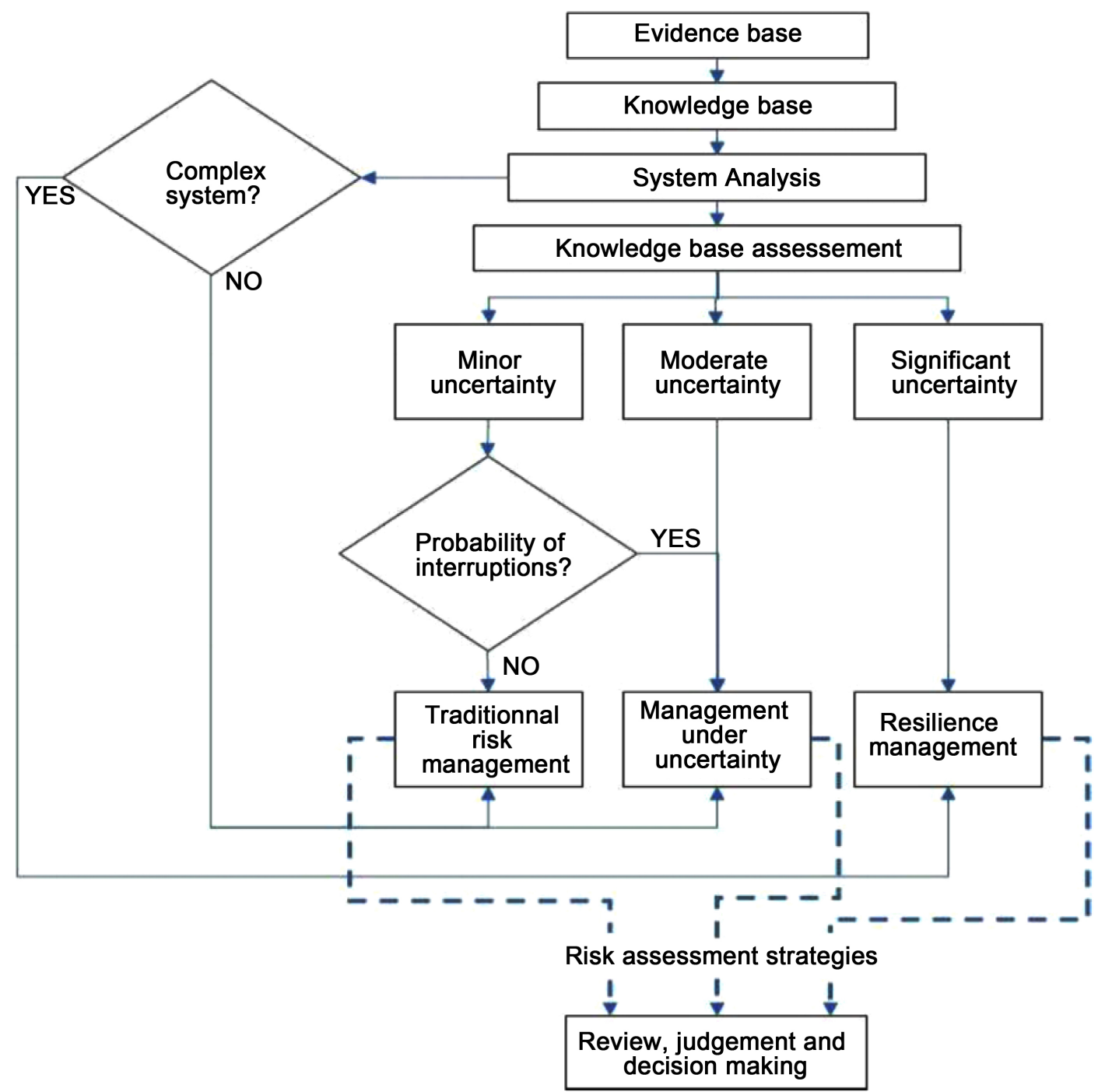

Figure 19. Steps in the decision-making under risk, uncertainty, and resilience framework. (Source: AbdulNour et al. (2021)).

\section{Acknowledgements}

The authors acknowledge the anonymous reviewers, whose critiques and suggestions improved the quality of this manuscript.

\section{Conflicts of Interest}

The authors declare no conflicts of interest regarding the publication of this paper.

\section{References}

Abdelgawad, M., \& Fayek, A. R. (2010). Risk Management in the Construction Industry Using Combined Fuzzy FMEA and Fuzzy AHP. Journal of Construction Engineering and Management, 136, 1028-1036.

https://doi.org/10.1061/(ASCE)CO.1943-7862.0000210

Abdul-Nour, G., Gauthier, F., Diallo, I., Komljenovic, D., Vaillancourt, R., \& Côté, A. 
(2021). Development of a Resilience Management Framework Adapted to Complex Asset Systems: Hydro-Québec Research Chair on Asset Management. In A. Crespo Marquez, D. Komljenovic, \& J. Amadi-Echendu (Eds.), 14th World Congress on Engineering Asset Management (pp. 126-136). Springer Science and Business Media Deutschland GmbH. https://doi.org/10.1007/978-3-030-64228-0 12

Adriaensen, A., Patriarca, R., Smoker, A., \& Bergström, J. (2019). A Socio-Technical Analysis of Functional Properties in a Joint Cognitive System: A Case Study in an Aircraft Cockpit. Ergonomics, 62, 1598-1616.

https://doi.org/10.1080/00140139.2019.1661527

Afuye, G. A., Kalumba, A. M., Busayo, E. T., \& Orimoloye, I. R. (2021). A Bibliometric Review of Vegetation Response to Climate Change. Environmental Science and Pollution Research, 28, 1-13. https://doi.org/10.1007/s11356-021-16319-7

Aguilera, M. V. C., da Fonseca, B. B., Ferris, T. K., Vidal, M. C. R., \& de Carvalho, P. V. R. (2016). Modelling Performance Variabilities in Oil Spill Response to Improve System Resilience. Journal of Loss Prevention in the Process Industries, 41, 18-30. https://doi.org/10.1016/j.jlp.2016.02.018

Albery, S., Borys, D., \& Tepe, S. (2016). Advantages for Risk Assessment: Evaluating Learnings from Question Sets Inspired by the FRAM and the Risk Matrix in a Manufacturing Environment. Safety Science, 89, 180-189.

https://doi.org/10.1016/j.ssci.2016.06.005

Allison, C. K., Revell, K. M., Sears, R., \& Stanton, N. A. (2017). Systems Theoretic Accident Model and Process (STAMP) Safety Modelling Applied to an Aircraft Rapid Decompression Event. Safety Science, 98, 159-166.

https://doi.org/10.1016/j.ssci.2017.06.011

https://www.sciencedirect.com/science/article/pii/S0925753516304945

Alm, H., \& Woltjer, R. (2010). Patient Safety Investigation through the Lens of FRAM. In Human Factors: A System View of Human, Technology and Organisation (pp. 53-65). Shaker Publishing.

Anvarifar, F., Voorendt, M. Z., Zevenbergen, C., \& Thissen, W. (2017). An Application of the Functional Resonance Analysis Method (FRAM) to Risk Analysis of Multifunctional Flood Defences in the Netherlands. Reliability Engineering \& System Safety, 158, 130-141. https://doi.org/10.1016/j.ress.2016.10.004

Appicharla, S. (2011). Modelling and Analysis of Herefordshire Level Crossing Accident Using Management Oversight and Risk Tree (MORT). In 6th IET International Conference on System Safety 2011 (pp. 1-10). Institution of Engineering and Technology. https://doi.org/10.1049/cp.2011.0259

Aria, M., \& Cuccurullo, C. (2017). Bibliometrix: An R-Tool for Comprehensive Science Mapping Analysis. Journal of Informetrics, 11, 959-975. https://doi.org/10.1016/j.joi.2017.08.007

Bellini, E., Coconea, L., \& Nesi, P. (2020). A Functional Resonance Analysis Method Driven Resilience Quantification for Socio-Technical Systems. IEEE Systems Journal, 14, 1234-1244. https://doi.org/10.1109/JSYST.2019.2905713

Bellini, E., Nesi, P., Pantaleo, G., \& Venturi, A. (2016). Functional Resonance Analysis Method Based-Decision Support Tool for Urban Transport System Resilience Management. In 2nd IEEE International Smart Cities Conference, ISC2 2016 (pp. 1-7). Institute of Electrical and Electronics Engineers Inc. https://doi.org/10.1109/ISC2.2016.7580833

Belmonte, F., Schön, W., Heurley, L., \& Capel, R. (2011). Interdisciplinary Safety Analysis of Complex Socio-Technological Systems Based on the Functional Resonance Accident 
Model: An Application to Railway Traffic Supervision. Reliability Engineering \& System Safety, 96, 237-249. https://doi.org/10.1016/j.ress.2010.09.006

Bjerga, T., Aven, T., \& Zio, E. (2016). Uncertainty Treatment in Risk Analysis of Complex Systems: The Cases of STAMP and FRAM. Reliability Engineering \& System Safety, 156, 203-209. https://doi.org/10.1016/j.ress.2016.08.004

Buikstra, E., Strivens, E., \& Clay-Williams, R. (2020). Understanding Variability in Discharge Planning Processes for the Older Person. Safety Science, 121, 137-146. https://doi.org/10.1016/j.ssci.2019.08.026

Cabrera, M. V., Vidal, M. C. R., Ferris, T. K., \& De Carvalho, P. V. R. (2014). Modeling Oil Spill Defense System Using Functional Resonance Analysis Method. In Process Safety Spotlights 2014-Topical Conference at the 2014 AIChE Spring Meeting and 10th Global Congress on Process Safety (pp. 1-8). AICE. ISBN: 978-0-8169-1083-0.

Center for Chemical Process Safety (1999). Guidelines for Chemical Process Quantitative Risk Analysis (2nd ed.). American Institute of Chemical Engineers.

Center for Chemical Process Safety (2008). Guidelines for Hazard Evaluation Procedures (3rd ed.). Wiley.

Chiozza, M. L., \& Ponzetti, C. (2009). FMEA: A Model for Reducing Medical Errors. Clinica Chimica Acta, 404, 75-78. https://doi.org/10.1016/j.cca.2009.03.015

Clay-Williams, R., Hounsgaard, J., \& Hollnagel, E. (2015). Where the Rubber Meets the Road: Using FRAM to Align Work-as-Imagined with Work-as-Done When Implementing Clinical Guidelines. Implementation Science, 10, 1-8.

https://doi.org/10.1186/s13012-015-0317-y

Cobo, M. J., López-Herrera, A. G., Herrera-Viedma, E., \& Herrera, F. (2011). An Approach for Detecting, Quantifying, and Visualizing the Evolution of a Research Field: A Practical Application to the Fuzzy Sets Theory Field. Journal of Informetrics, 5, 146166. https://doi.org/10.1016/j.joi.2010.10.002

Costantino, F., Di Gravio, G., \& Tronci, M. (2018). Environmental Audit Improvements in Industrial Systems through FRAM. IFAC-PapersOnLine, 51, 1155-1161. https://doi.org/10.1016/j.ifacol.2018.08.434

Dai, W., Maropoulos, P. G., Cheung, W. M., \& Tang, X. (2011). Decision-Making in Product Quality Based on Failure Knowledge. International Journal of Product Lifecycle Management, 5, 143-163. https://doi.org/10.1504/IJPLM.2011.043185

Das, P., Benneyan, J., Powers, L., Carmody, M., Kerwin, J., \& Singer, S. (2018). Engineering Safer Care Coordination from Hospital to Home: Lessons from the USA. Future Healthcare Journal, 5, 164. https://doi.org/10.7861/futurehosp.5-3-164

De Carvalho, P. V. R. (2011). The Use of Functional Resonance Analysis Method (FRAM) in a Mid-Air Collision to Understand Some Characteristics of the Air Traffic Management System Resilience. Reliability Engineering and System Safety, 96, 1482-1498. https://doi.org/10.1016/j.ress.2011.05.009

de Vries, L. (2017). Work as Done? Understanding the Practice of Sociotechnical Work in the Maritime Domain. Journal of Cognitive Engineering and Decision Making, 11, 270295. https://doi.org/10.1177/1555343417707664

Diop, I., AbdulNour, G., \& Komljenovic, D. (2021). Overview of Strategic Approach to Asset Management and Decision-Making. International Journal of Engineering and Technical Research (IJERT), 10, 64-89.

Diop, I., Nadeau, S., \& Emami-Mehrgani, B. (2019). A Mathematical Model: A Flexible Manufacturing System, Prone to Error, Making Two Products Each with Stochastic Demand Schedules. American Journal of Industrial and Business Management, 9, 139168. https://doi.org/10.4236/ajibm.2019.91011 
Duan, G., Tian, J., \& Wu, J. (2015). Extended FRAM by Integrating with Model Checking to Effectively Explore Hazard Evolution. Mathematical Problems in Engineering, 2015, Article ID: 196107. https://doi.org/10.1155/2015/196107

Ellegaard, O., \& Wallin, J. A. (2015). The Bibliometric Analysis of Scholarly Production: How Great Is the Impact? Scientometrics, 105, 1809-1831.

https://doi.org/10.1007/s11192-015-1645-z

Falegnami, A., Costantino, F., Di Gravio, G., \& Patriarca, R. (2019). Unveil Key Functions in Socio-Technical Systems: Mapping FRAM into a Multilayer Network. Cognition, Technology \& Work, 22, 877-899. https://doi.org/10.1007/s10111-019-00612-0

Ferjencik, M. (2011). An Integrated Approach to the Analysis of Incident Causes. Safety Science, 49, 886-905. https://doi.org/10.1016/j.ssci.2011.02.005

Ferreira, P. N., \& Cañas, J. J. (2019). Assessing Operational Impacts of Automation Using Functional Resonance Analysis Method. Cognition, Technology \& Work, 21, 535-552. https://doi.org/10.1007/s10111-019-00540-Z

França, J. E. M., Hollnagel, E., dos Santos, I. J. A. L., \& Haddad, A. N. (2021). Analysing Human Factors and Non-Technical Skills in Offshore Drilling Operations Using FRAM (Functional Resonance Analysis Method). Cognition, Technology and Work, 23, 553 566. https://doi.org/10.1007/s10111-020-00638-9

França, J. E., Hollnagel, E., dos Santos, I. J. L., \& Haddad, A. N. (2019). FRAM AHP Approach to Analyse Offshore Oil Well Drilling and Construction Focused on Human Factors. Cognition, Technology \& Work, 22, 653-665.

https://doi.org/10.1007/s10111-019-00594-Z

Furniss, D., Curzon, P., \& Blandford, A. (2016). Using FRAM beyond Safety: A Case Study to Explore How Sociotechnical Systems Can Flourish or Stall. Theoretical Issues in Ergonomics Science, 17, 507-532. https://doi.org/10.1080/1463922X.2016.1155238

Gao, Y., Fan, Y., Wang, J., \& Duan, Z. (2019). Evaluation of Governmental Safety Regulatory Functions in Preventing Major Accidents in China. Safety Science, 120, 299-311. https://doi.org/10.1016/j.ssci.2019.07.002

Gattola, V., Patriarca, R., Tomasi, G., \& Tronci, M. (2018). Functional Resonance in Industrial Operations: A Case Study in a Manufacturing Plant. IFAC-PapersOnLine, 51, 927-932. https://doi.org/10.1016/j.ifacol.2018.08.489

Goldberg, B. E., Everhart, K., Stevens, R., Babbitt III, N., Clemens, P., \& Stout, L. (1994). System Engineering Toolbox for Design-Oriented Engineers. No. NAS 1.61: 1358.

Herrera, I. A., \& Woltjer, R. (2010). Comparing a Multi-Linear (STEP) and Systemic (FRAM) Method for Accident Analysis. Reliability Engineering \& System Safety, 95, 1269-1275. https://doi.org/10.1016/j.ress.2010.06.003

Hirsch, J. E. (2005). An Index to Quantify an Individual's Scientific Research Output. Proceedings of the National Academy of Sciences, 102, 16569-16572. https://doi.org/10.1073/pnas.0507655102

Hollnagel, E. (1998). Cognitive Reliability and Error Analysis Method (CREAM). Elsevier.

Hollnagel, E. (2004). Barriers and Accident Prevention. Ashgate.

Hollnagel, E. (2012). FRAM: The Functional Resonance Analysis Method: Modelling Complex Socio-Technical Systems (pp. 1-142). Ashgate Publishing Ltd.

Hollnagel, E. (2013). Resilience Engineering in Practice: A Guidebook. Ashgate Publishing, Ltd.

Hollnagel, E. (2014). Safety-I and Safety-II. The Past and Future of Safety Management. Ashgate. 
Hollnagel, E. (2016). A FRAM Glossary. https://www.functionalresonance.com

Hollnagel, E. (2018). Safety-I and Safety-II: The Past and Future of Safety Management. CRC Press. https://doi.org/10.1201/9781315607511

Hollnagel, E., Hounsgaard, J., \& Colligan, L. (2014). FRAM-the Functional Resonance Analysis Method: A Handbook for the Practical Use of the Method. Centre for Quality, Region of Southern Denmark.

Hollnagel, E., Pruchnicki, S., Woltjer, R., \& Etcher, S. (2008). Analysis of Comair Flight 5191 with the Functional Resonance Accident Model. In 8th International Symposium of the Australian Aviation Psychology Association (pp. 1-8). Hal Open Science.

Hollnagel, E., Woods, D. D., \& Leveson, N. (2012). Resilience Engineering: Concepts and Precepts (pp. 1-397). Ashgate Publishing Ltd.

Hounsgaard, J. (2016). Patient Safety in Everyday Work: Learning from Things That Go Right. Master's Thesis, Syddansk Universitet.

Huang, W., Shuai, B., Zuo, B., Xu, Y., \& Antwi, E. (2019). A Systematic Railway Dangerous Goods Transportation System Risk Analysis Approach: The 24 Model. Journal of Loss Prevention in the Process Industries, 61, 94-103. https://doi.org/10.1016/j.jlp.2019.05.021

Jensen, A., \& Aven, T. (2017). Hazard/Threat Identification: Using Functional Resonance Analysis Method in Conjunction with the Anticipatory Failure Determination Method. Proceedings of the Institution of Mechanical Engineers, Part O: Journal of Risk and Reliability, 231, 383-389. https://doi.org/10.1177/1748006X17698067

Johnson, W. G. (1973). The Management Oversight and Risk Tree (MORT). Journal of Safety Research, 7, 4-15.

Kaya, G. K., \& Hocaoglu, M. F. (2020). Semi-Quantitative Application to the Functional Resonance Analysis Method for Supporting Safety Management in a Complex HealthCare Process. Reliability Engineering and System Safety, 202, Article ID: 106970. https://doi.org/10.1016/j.ress.2020.106970

Kaya, G. K., Ovali, H. F., \& Ozturk, F. (2019). Using the Functional Resonance Analysis Method on the Drug Administration Process to Assess Performance Variability. Safety Science, 118, 835-840. https://doi.org/10.1016/j.ssci.2019.06.020

Kaya, G. K., Ozturk, F., \& Sariguzel, E. E. (2021). System-Based Risk Analysis in a Tram Operating System: Integrating Monte Carlo Simulation with the Functional Resonance Analysis Method. Reliability Engineering and System Safety, 215, Article ID: 107835. https://doi.org/10.1016/j.ress.2021.107835

Lacey, P. (2011). An Application of Fault Tree Analysis to the Identification and Management of Risks in Government Funded Human Service Delivery. In Proceedings of the 2nd International Conference on Public Policy and Social Sciences (pp. 1-15). SSRN (Social Science Research Network).

Lee, J., \& Chung, H. (2018). A New Methodology for Accident Analysis with Human and System Interaction Based on FRAM: Case Studies in Maritime Domain. Safety Science, 109, 57-66. https://doi.org/10.1016/j.ssci.2018.05.011

Leveson, N. (2004). A New Accident Model for Engineering Safer Systems. Safety Science, 42, 237-270. https://doi.org/10.1016/S0925-7535(03)00047-X

Leveson, N. G. (2016). Engineering a Safer World: Systems Thinking Applied to Safety (p. 560). The MIT Press.

Lotka, A. J. (1926). The Frequency Distribution of Scientific Productivity. Journal of the Washington Academy of Sciences, 16, 317-323. 
Lundblad, K., Speziali, J., Woltjer, R., \& Lundberg, J. (2008). FRAM as a Risk Assessment Method for Nuclear Fuel Transportation. In Proceedings of the 4th International Conference Working on Safety (pp. 1-8).

Macchi, L. (2010). A Resilience Engineering Approach for the Evaluation of Performance Variability: Development and Application of the Functional Resonance Analysis Method for Air Traffic Management Safety Assessment. Ph.D. Thesis, École Nationale Supérieure des Mines de Paris.

Martyn, J. (1964). Bibliographic Coupling. Journal of Documentation, 20, 236-236. https://doi.org/10.1108/eb026352

McGill, A., Smith, D., McCloskey, R., Morris, P., Goudreau, A., \& Veitch, B. (2021). The Functional Resonance Analysis Method as a Healthcare Research Methodology: A Scoping Review Protocol. JBI Evidence Synthesis, 19, 734-740.

https://doi.org/10.11124/JBIES-20-00237

Melanson, A., \& Nadeau, S. (2019). Resilience Engineering for Sustainable Prevention in the Manufacturing Sector: A Comparative Study of Two Methods of Risk Analysis. American Journal of Industrial and Business Management, 9, 267-281. https://doi.org/10.4236/ajibm.2019.91017

Moher, D., Liberati, A., Tetzlaff, J., Altman, D. G., \& Prisma Group (2009). Preferred Reporting Items for Systematic Reviews and Meta-Analyses: The PRISMA Statement. PLoS Medicine, 6, e1000097. https://doi.org/10.1371/journal.pmed.1000097

Nakajima, K. (2017). Blood Transfusion with Health Information Technology in Emergency Settings from a Safety-II Perspective. In Resilient Health Care (Volume 2, pp. 129-144). CRC Press. https://doi.org/10.1201/9781315605739-14

Nemeth, C. P., \& Hollnagel, E. (2016). Resilience Engineering in Practice, Volume 2: Becoming Resilient. CRC Press. https://doi.org/10.1201/9781315605708

Ouyang, M., Hong, L., Yu, M.-H., \& Fei, Q. (2010). STAMP-Based Analysis on the Railway Accident and Accident Spreading: Taking the China-Jiaoji Railway Accident for Example. Safety Science, 48, 544-555. https://doi.org/10.1016/j.ssci.2010.01.002

Pardo-Ferreira, M. C., Martínez-Rojas, M., Salguero-Caparrós, F., \& Rubio-Romero, J. C. (2019). Evolution of the Functional Resonance Analysis Method (FRAM) through the Combination with Other Methods. Direccion y Organizacion, 68, 41-50. https://doi.org/10.37610/dyo.v0i68.550

Patriarca, R., Di Gravio, G., \& Costantino, F. (2017a). A Monte Carlo Evolution of the Functional Resonance Analysis Method (FRAM) to Assess Performance Variability in Complex Systems. Safety Science, 91, 49-60. https://doi.org/10.1016/j.ssci.2016.07.016

Patriarca, R., Di Gravio, G., \& Costantino, F. (2018). MyFRAM: An Open Tool Support for the Functional Resonance Analysis Method. In 2nd International Conference on System Reliability and Safety, ICSRS 2017 (pp. 1-5). Institute of Electrical and Electronics Engineers Inc. https://doi.org/10.1109/ICSRS.2017.8272861

Patriarca, R., Di Gravio, G., Costantino, F., \& Tronci, M. (2017b). The Functional Resonance Analysis Method for a Systemic Risk Based Environmental Auditing in a Sinter Plant: A Semi-Quantitative Approach. Environmental Impact Assessment Review, 63, 72-86. https://doi.org/10.1016/j.eiar.2016.12.002

Patriarca, R., Di Gravio, G., Woltjer, R., Costantino, F., Praetorius, G., Ferreira, P., \& Hollnagel, E. (2020). Framing the FRAM: A Literature Review on the Functional Resonance Analysis Method. Safety Science, 129, Article ID: 104827. https://doi.org/10.1016/j.ssci.2020.104827

Praetorius, G., \& Kataria, A. (2016). Chapter 8. Resilience and Complexity in a Maritime Service Supply Chain's Everyday Operation. In T.-M. Choi (Ed.), Service Supply Chain 
Systems: A Systems Engineering Approach (pp. 121-137). CRC Press. https://doi.org/10.1201/b20894-16

Praetorius, G., Hollnagel, E., \& Dahlman, J. (2015). Modelling Vessel Traffic Service to Understand Resilience in Everyday Operations. Reliability Engineering \& System Safety, 141, 10-21. https://doi.org/10.1016/j.ress.2015.03.020

Raben, D. C., Viskum, B., Mikkelsen, K. L., Hounsgaard, J., Bogh, S. B., \& Hollnagel, E. (2018). Application of a Non-Linear Model to Understand Healthcare Processes: Using the Functional Resonance Analysis Method on a Case Study of the Early Detection of Sepsis. Reliability Engineering and System Safety, 177, 1-11.

https://doi.org/10.1016/j.ress.2018.04.023

Rasmussen, J. (1997). Risk Management in a Dynamic Society: A Modelling Problem. Safety Science, 27, 183-213. https://doi.org/10.1016/S0925-7535(97)00052-0

Rasmussen, J., Pejtersen, A., \& Goodstein, L. (1994). Cognitive Systems Engineering. John Wiley \& Sons.

Rausand, M., \& Hoyland, A. (2004). System Reliability Theory: Models, Statistical Methods, and Applications (2nd ed., Volume 396, p. 88). John Wiley \& Sons.

Reason, J. (1990). Human Error. Cambridge University Press. https://doi.org/10.1017/CBO9781139062367

Ropohl, G. (1999). Philosophy of Socio-Technical Systems. Society for Philosophy and Technology Quarterly Electronic Journal, 4, 186-194. https://doi.org/10.5840/techne19994311

Rosa, L. V., Haddad, A. N., \& de Carvalho, P. V. R. (2015). Assessing Risk in Sustainable Construction Using the Functional Resonance Analysis Method (FRAM). Cognition, Technology and Work, 17, 559-573. https://doi.org/10.1007/s10111-015-0337-Z

Salehi, V., Hanson, N., Smith, D., McCloskey, R., Jarrett, P., \& Veitch, B. (2021). Modeling and Analyzing Hospital to Home Transition Processes of Frail Older Adults Using the Functional Resonance Analysis Method (FRAM). Applied Ergonomics, 93, Article ID: 103392. https://doi.org/10.1016/j.apergo.2021.103392

Salmon, P. M., Cornelissen, M., \& Trotter, M. J. (2012). Systems-Based Accident Analysis Methods: A Comparison of Accimap, HFACS, and STAMP. Safety Science, 50, 11581170. https://doi.org/10.1016/j.ssci.2011.11.009

Sawaragi, T., Horiguchi, Y., \& Hina, A. (2006). Safety Analysis of Systemic Accidents Triggered by Performance Deviation. In 2006 SICE-ICASE International Joint Conference (pp. 1778-1781). IEEE. https://doi.org/10.1109/SICE.2006.315635

Slater, D., Hollnagel, E., MacKinnon, R., Sujan, M., Carson-Stevens, A., Ross, A., \& Bowie, P. (2022). A Systems Analysis of the COVID-19 Pandemic Response in the United Kingdom-Part 1-The Overall Context. Safety Science, 146, Article ID: 105525. https://doi.org/10.1016/j.ssci.2021.105525

Slim, H. (2020). A Proposal of a Mixed Fuzzy Logic/Rough Sets FRAM Model for Complex Systemic Analyses of Sociotechnical Systems. Ph.D. Thesis, École de technologie supérieure de Montréal.

Smith, D., Veitch, B., Khan, F., \& Taylor, R. (2020). Integration of Resilience and FRAM for Safety Management. ASCE-ASME Journal of Risk and Uncertainty in Engineering Systems, Part A: Civil Engineering, 6, Article ID: 04020008.

https://doi.org/10.1061/AJRUA6.0001044

Smoczyński, P., Kadziński, A., \& Gill, A. (2018a). Simulating the World Described with the Functional Resonance Analysis Method. In 28th International European Safety and Reliability Conference, ESREL (pp. 1247-1252). CRC Press/Balkema. https://doi.org/10.1201/9781351174664-157 
Smoczyński, P., Kadziński, A., Gill, A., \& Anna, K. T. (2018b). Applicability of the Functional Resonance Analysis Method in Urban Transport. MATEC Web of Conferences, 231, Article No. 05006. https://doi.org/10.1051/matecconf/201823105006

Sujan, M.-A., \& Felici, M. (2012). Combining Failure Mode and Functional Resonance Analyses in Healthcare Settings. In International Conference on Computer Safety, Reliability, and Security (pp. 364-375). Springer.

https://doi.org/10.1007/978-3-642-33678-2 31

Toroody, A. B., Abaei, M. M., \& Gholamnia, R. (2016). Conceptual Compression Discussion on a Multi-Linear (FTA) and Systematic (FRAM) Method in an Offshore Operation's Accident Modeling. International Journal of Occupational Safety and Ergonomics, 22, 532-540. https://doi.org/10.1080/10803548.2016.1157399

U.S. Department of Labor Occupational Safety and Health Administration Process (1994). Safety Management Guidelines for Compliance. U.S. Government Printing Office. OSHA 3133.

Van Eck, N. J., \& Waltman, L. (2013). VOSviewer Manual. Leiden: Univeristeit Leiden, 1-53.

Woltjer, R., \& Hollnagel, E. (2007). The Alaska Airlines Flight 261 Accident: A Systemic Analysis of Functional Resonance. In 2007 International Symposium on Aviation Psychology (pp. 763-768). CORE Scholar.

https://corescholar.libraries.wright.edu/isap 2007/4

Yousefi, A., Rodriguez Hernandez, M., \& Lopez Peña, V. (2019). Systemic Accident Analysis Models: A Comparison Study between AcciMap, FRAM, and STAMP. Process Safety Progress, 38, e12002. https://doi.org/10.1002/prs.12002

Zhang, J., Yu, Q., Zheng, F., Long, C., Lu, Z., \& Duan, Z. (2016). Comparing Keywords plus of WOS and Author Keywords: A Case Study of Patient Adherence Research. Journal of the Association for Information Science and Technology, 67, 967-972. https://doi.org/10.1002/asi.23437 


\section{Appendices}

\section{Appendix 1-Three-Fields Plot}

Figure A1 illustrates the Three-Fields Plot: Country (AU_CO), Authors (AU), Keywords Plus (ID).

AU_CO

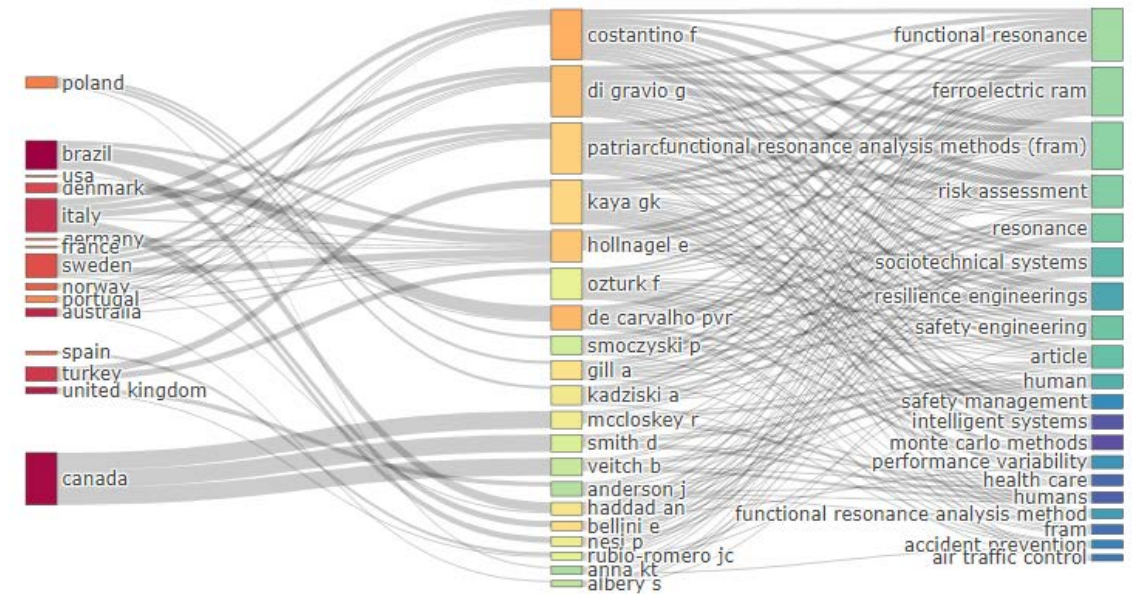

Figure A1. Three-Fields plot: Country (AU_CO), Authors (AU), Keywords Plus (ID) (Source: own representation). 